\title{
Machine Learning Approaches for Activity Recognition and/or Activity Prediction in Locomotion Assistive Devices-A Systematic Review
}

\author{
Floriant Labarrière ${ }^{1}\left(\mathbb{D}\right.$, Elizabeth Thomas ${ }^{1}$, Laurine Calistri ${ }^{2}$, Virgil Optasanu ${ }^{3}{ }^{(\mathbb{D}}$, \\ Mathieu Gueugnon ${ }^{\text {, Paul Ornetti }}{ }^{1,4,5}$ (D) and Davy Laroche $1,4, *$ (D) \\ 1 INSERM, UMR1093-CAPS, Université de Bourgogne Franche Comté, UFR des Sciences du Sport, \\ F-21000 Dijon, France; floriant_labarriere@etu.u-bourgogne.fr (F.L.); elizabeth.thomas@u-bourgogne.fr (E.T.); \\ paul.ornetti@chu-dijon.fr (P.O.) \\ 2 PROTEOR, 6 rue de la Redoute, CS 37833, CEDEX 21078 Dijon, France; Laurine.Calistri@proteor.com \\ 3 ICB, UMR 6303 CNRS, Université de Bourgogne Franche Comté 9 Av. Alain Savary, CEDEX 21078 Dijon, \\ France; virgil.optasanu@u-bourgogne.fr \\ 4 INSERM, CIC 1432, Module Plurithematique, Plateforme d'Investigation Technologique, \\ CHU Dijon-Bourgogne, Centre d'Investigation Clinique, Module Plurithématique, \\ Plateforme d'Investigation Technologique, 21079 Dijon, France; mathieu.gueugnon@chu-dijon.fr \\ 5 Department of Rheumatology, Dijon University Hospital, 21079 Dijon, France \\ * Correspondence: davy.laroche@chu-dijon.fr; Tel.: +33-380295665
}

Received: 25 September 2020; Accepted: 4 November 2020; Published: 6 November 2020

\begin{abstract}
Locomotion assistive devices equipped with a microprocessor can potentially automatically adapt their behavior when the user is transitioning from one locomotion mode to another. Many developments in the field have come from machine learning driven controllers on locomotion assistive devices that recognize/predict the current locomotion mode or the upcoming one. This review synthesizes the machine learning algorithms designed to recognize or to predict a locomotion mode in order to automatically adapt the behavior of a locomotion assistive device. A systematic review was conducted on the Web of Science and MEDLINE databases (as well as in the retrieved papers) to identify articles published between 1 January 2000 to 31 July 2020. This systematic review is reported in accordance with the Preferred Reporting Items for Systematic reviews and Meta-Analyses (PRISMA) guidelines and is registered on Prospero (CRD42020149352). Study characteristics, sensors and algorithms used, accuracy and robustness were also summarized. In total, 1343 records were identified and 58 studies were included in this review. The experimental condition which was most often investigated was level ground walking along with stair and ramp ascent/descent activities. The machine learning algorithms implemented in the included studies reached global mean accuracies of around $90 \%$. However, the robustness of those algorithms seems to be more broadly evaluated, notably, in everyday life. We also propose some guidelines for homogenizing future reports.
\end{abstract}

Keywords: machine learning; locomotion; assistive devices; embedded sensors

\section{Introduction}

Healthy humans are easily able to adjust locomotor pattern to deal with multiple environments encountered in daily living situations such as stair ascent/descent, slope ascent/descent, obstacle clearance, walking on uneven floors, cross-slopes or different surfaces. Hence, with lower limb impairments such as unilateral lower limb amputation, it becomes challenging to deal with most of these environmental changes [1]. 
To handle this issue, intelligent devices such as the C-leg TM (ОТТОВOCK, Berlin, Germany) or the Rheo knee (ÖSSUR, Reykjavík, Iceland) have been developed. These variable-damping prostheses, compared to mechanically passive prostheses, improved the smoothness of gait, and decreased hip work during level-ground walking [2]. Additional improvement was provided by a powered prosthesis which was reported to decrease the metabolic cost of transport when compared to a conventional passive prosthesis in similar conditions [3]. Prosthetic devices which passively or actively mimicked human actions were found to be of help. One historic example of such innovation was the energy return foot that reproduced foot behavior and improved the gait of patients with amputation. Other innovations in the attempt to create intelligent devices can be seen with some microprocessor-controlled prostheses with the ability to recognize the terrain being traversed (e.g., Genium OTTOBOCK, Berlin, Germany, Linx BLATCHFORD, Basingstoke, UK). It only stands to reason that the next step in this progression would be the development of devices with the ability to make predictions for automatic gait adjustments across multiple terrains.

Developments in these efforts have come in the form of intelligent controllers on locomotion assistive devices. In such devices, gait is regulated by a hierarchical three-level controller [4]. The highest-level controller is responsible for detecting the user-intent. The mid-level controller automatically switches the control law (e.g., the powered active transfemoral prosthesis developed by Vanderbilt University [5]) of the device in accordance with the high-level controller output. The low-level controller compares the desired state of the device to the sensed state and corrects it when needed. The detection of user-intent is done either by the user directly communicating his intentions to the device using a controller, or by automatic interpretation by an algorithm. Examples of the first are the control buttons found in the ReWalk TM exoskeleton (ARGO MEDICAL TECHNOLOGIES Ltd., Yokneam, Israel) or predefined body movements which allow the wearer of the Power KneeTM (ÖSSUR, Reykjavík, Iceland) to switch between locomotion modes. In this device, switching between locomotion modes requires the user to stop or to perform certain unnatural body movements. As opposed to these explicit methods, algorithm-based implicit methods interpret user intent. Such algorithm-based techniques allow smoother transitions by automatically switching between the control laws of the device. A more promising approach might be one based on machine learning algorithms. Such algorithms automatically detect user-intent by mapping sensor data to an associated locomotion task.

There are numerous studies in which machine learning has been used to adapt the behavior of orthotic/prosthetic devices to user locomotion mode. We performed a systematic review that identifies and summarizes such studies. Under the scope of this review, reports were selected if (1) body-worn sensors or sensors embedded in the devices were used (2) machine learning classifiers were able to identify the investigated locomotion modes of human volunteers. It covers essential technical details such as the pre-processing methods which were used, the specific Machine Learning algorithms which were employed, and the corresponding accuracies obtained. By the end of this review we aim to propose recommendations for future studies and some suggestions concerning the uniformization of the terms used to report results in the field.

\section{Material and Methods}

This systematic review, registered on PROSPERO (CRD42020149352), is reported in accordance with the Preferred Reporting Items for Systematic reviews and Meta-Analyses (PRISMA) guidelines [6].

\subsection{Eligibility Criteria}

This systematic review included peer-reviewed articles and patents focusing on the Machine Learning (ML) approach for classifying locomotion modes in volunteers wearing assistive devices (see below for definition of the included devices). For this purpose:

- The algorithms must be based on locomotion data collected from embedded sensors in the device or from body-worn sensors. Studies evaluating a previously developed ML-based pattern recognition algorithms were also included. We focused on Machine Learning methods that carried 
out classification for recognizing locomotion modes. Studies using a Machine Learning regression approach were excluded.

- The articles must be related to locomotion in various environments, e.g., level ground walking, stair ascent/descent, ramp ascent/descent, obstacle clearance, walking on a cross-slope, turning, walking on different surfaces, ... Studies were included if at least two locomotion modes were investigated.

- Only lower limb assistive devices such as exoskeletons, prostheses (for below or above knee amputation) or orthoses were considered.

- Studies were excluded if they met at least one of the following exclusion criteria: (1) non-human (robots or animals), (2) volunteers who are minors (under 18 years old), (3) studies focusing on volunteers equipped with an upper-limb device.

\subsection{Information Sources}

The PubMed and Web of Knowledge (including Web of Science core collection, Derwent Innovation Index, Russian Citation index, SciELO Citation Index) databases were searched on 31 July 2020. The two search strings used are given in the Supplementary Material. Published articles in English between 1 January 2000 and 31 July 2020 were included. Systematic reviews and meta-analyses were excluded. Conference papers were excluded if a corresponding published peer-reviewed article by the same authors had been included. Additional articles were included by further searching the references within the papers which were first identified by the search strategy described above.

\subsection{Study Selection}

The search strings were defined and validated by all authors. One person (FL) performed the initial search and removed the duplicates. Two main readers (DL, FL) independently screened the titles and the abstracts of all articles identified during the initial search. In case of disagreement, a third reader (LC) decided to include/exclude the article. Afterwards, the two readers (DL, FL) read the full text of the articles which had been picked from the previous step and checked them for eligibility using the criteria of our Modified QualSyst Tool which can be found in the Supplementary Material of this article. The process used to create the Modified QualSyst Tool can be found in the Section 2.4.1. Any disagreements on the eligibility of an article were resolved by the third person (LC).

\subsection{Quality Assessment in Included Articles}

The quality of the included articles was assessed with a dedicated QualSyst Tool [7] modified for the purposes of studying Machine Learning algorithms implemented on locomotion assistive devices. In the sections below, we provide further explanations of the score assignment for each article using this tool.

\subsubsection{Creating the Modified QualSyst Tool}

Our first step was to remove irrelevant items from the QualSyst Tool [7] (Criteria 3 and 5 to 12 , e.g., blinding of investigators, of subjects, etc.). Next, we added items which are relevant to the implementation of Machine Learning algorithms such as analysis windows, selected features, evaluation method of the algorithm, etc. All items were validated by all the authors and the quality of included articles was assessed by the main readers (FL, DL). The final version of this Modified QualSyst Tool can be found in the Supplementary Material of this article.

\subsubsection{Rating Articles Using the Modified QualSyst Tool}

Twelve items were used for rating the articles. For each item, the article was rated with a score between 0 and 2 (with 2 indicating full supply of information, 1 a partial supply and 0 no information provided). Guidelines to allow consistent ratings across the included papers were created. These 
guidelines are provided in the Supplementary Material. The description of the twelve items were as follows:

- The first two items evaluated if the hypotheses and objectives of the study were sufficiently described and if the study design was appropriate.

- Item 3 evaluated if the volunteer characteristics were sufficiently described.

- Items 4 to 10 evaluated if the Machine Learning approach was sufficiently described to allow repeatability.

- Items 11 and 12 evaluated if the results were reported with enough details and if the conclusions were in accordance with them.

The score of each article was computed as the average of the 12 rated items. The maximum score possible for an article was 2. The score from 0-2 was transformed to a scale of $0-100 \%$ for ease of comprehension ( 0 indicating no information provided at all and 100 with maximum lucidity). More details on this scoring procedure and the guidelines used can be found in the Supplementary Material.

\subsection{Synthesis of the Results}

The following elements were extracted and grouped from the included studies:

- Investigated population (pathology and number of volunteers) and type of assistive device (above-knee prosthesis or below-knee prosthesis or orthosis or exoskeleton).

- The main elements of the experimental protocol are reported.

- The studied locomotor activities along with the walking speed of the volunteers are given.

- The 'Critical Timing' is reported. It is the latest moment when the behavior of the locomotion assistive device can be adapted to the new locomotion mode without disturbing the user.

$\bigcirc \quad$ The type of sensors used in each study along with the total number of measurement axes per sensor are reported.

○ Details on the machine learning algorithm implementation are also reported (online and/or offline implementation; forward prediction and/or backward recognition [8]).

- The signal processing techniques and Machine Learning algorithms used are reported as well:

This includes the type and length of the analysis windows.

The extracted features used for the analyses. If several configurations were tested, only the optimal configuration is given.

$\bigcirc \quad$ The machine learning algorithms are provided. Overall results of the machine learning algorithms are reported in terms of accuracy (A). So, if studies indicated the error rates (E), the corresponding mean overall accuracy was computed $(A=100-E$ in percent). For studies recruiting both healthy volunteers and patients, the reported accuracy of the machine learning algorithms corresponded to the patients (accuracy).

\section{Results}

\subsection{Study Selection}

The literature search produced 288 articles on PubMed and 1078 articles on Web of Science. Additionally, four studies were manually identified from references in the articles and added to the review. After removing the duplicates, there remained 1343 articles for screening. On the basis of titles and abstracts screening, 1267 articles were excluded from the review. Two authors independently read the full texts of the remaining 76 articles and checked them for eligibility. Finally, 58 articles were considered eligible to be included in this review. The PRISMA Flow Chart [6] is provided (Figure 1). 


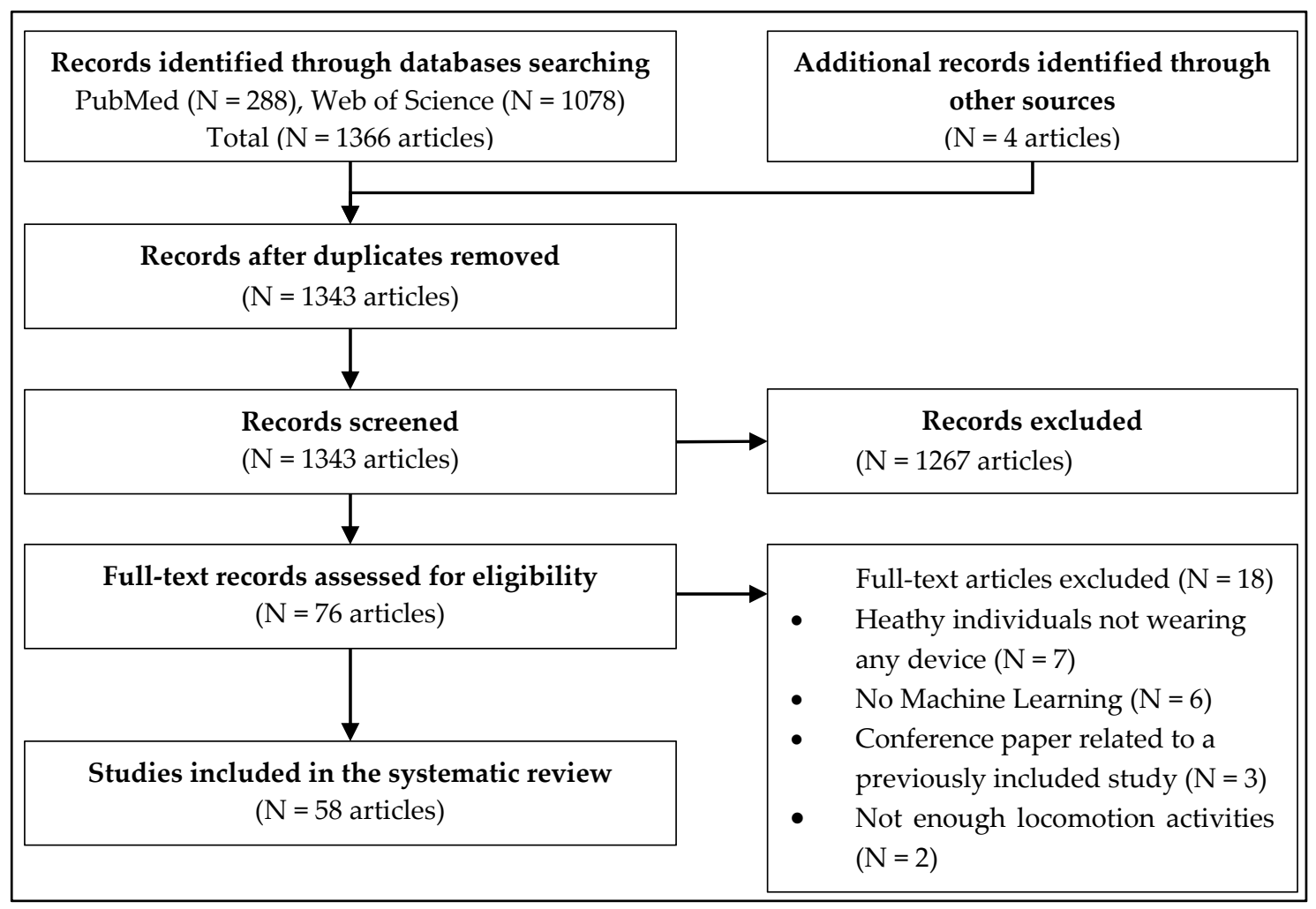

Figure 1. Preferred Reporting Items for Systematic reviews and Meta-Analyses (PRISMA) flow chart of the systematic review.

\subsection{Quality of the Included Studies}

The mean quality score of each study using the items of the Modified QualSyst Tool is provided in Table 1 and the detailed quality scores are presented in the Supplementary Material. The mean quality score was $68.4 \%+/-13.4$ for the articles.

Table 1. Quality assessment and recruited volunteers in the included studies.

\begin{tabular}{llll}
\hline Article & Quality Score & Groups (N) & Locomotion Assistive Device \\
\hline Ai et al. 2017 [9] & $70.8 \%$ & TT (4)/Healthy (1) & Ankle Prosthesis \\
Beil et al. 2018 [10] & $90.9 \%$ & Healthy (10) & Exoskeleton \\
Chen et al. 2013 [11] & $72.7 \%$ & TT (5)/Healthy (8) & Ankle Prosthesis \\
Chen et al. 2014 [12] & $79.2 \%$ & TT (1)/Healthy (7) & Ankle Prosthesis \\
Chen et al. 2015 [13] & $77.3 \%$ & TT (1)/Healthy (5) & Ankle Prosthesis \\
Du et al. 2012 [14] & $75.0 \%$ & TF (9) & Ankle Knee Prosthesis \\
Du et al. 2013 [15] & $45.8 \%$ & TF (4) & Ankle Knee Prosthesis \\
Feng et al. 2019 [16] & $77.3 \%$ & TT (3) & Ankle Prosthesis \\
Godiyal et al. 2018 [17] & $86.4 \%$ & TF (2)/Healthy (8) & Ankle Knee Prosthesis \\
Gong et al. 2018 [18] & $86.4 \%$ & Healthy (1) & Orthosis \\
Gong et al. 2020 [19] & $86.4 \%$ & Healthy (3) & Orthosis \\
Hernandez et al. 2012 [20] & $37.5 \%$ & TF (1) & Ankle Knee Prosthesis \\
Hernandez et al. 2013 [21] & $54.2 \%$ & Healthy (1) & Ankle Knee Prosthesis \\
Huang et al. 2009 [22] & $81.8 \%$ & TF (2)/Healthy (8) & Ankle Knee Prosthesis \\
Huang et al. 2010 [23] & $79.2 \%$ & TF (1)/Healthy (5) & Ankle Knee Prosthesis \\
Huang et al. 2011 [24] & $83.3 \%$ & TF (5) & Ankle Knee Prosthesis \\
Kim et al. 2017 [25] & $63.6 \%$ & Healthy (8) & Exoskeleton \\
Liu et al. 2016 [26] & $70.8 \%$ & TF (1)/Healthy (6) & Ankle Knee Prosthesis \\
\hline
\end{tabular}


Table 1. Cont.

\begin{tabular}{|c|c|c|c|}
\hline Article & Quality Score & Groups (N) & Locomotion Assistive Device \\
\hline Liu et al. 2017 [27] & $66.7 \%$ & TF (2)/Healthy (2) & Ankle Knee Prosthesis \\
\hline Liu et al. 2017 [28] & $63.6 \%$ & TF (2)/Healthy (3) & Ankle Knee Prosthesis \\
\hline Long et al. 2016 [29] & $83.3 \%$ & Healthy (3) & Exoskeleton \\
\hline Mai et al. 2011 [30] & $50.0 \%$ & TT (1) & Ankle Prosthesis \\
\hline Mai et al. 2018a [31] & $45.8 \%$ & TT (1) & Ankle Prosthesis \\
\hline Mai et al. 2018b [32] & $54.2 \%$ & TT (1) & Ankle Prosthesis \\
\hline Miller et al. 2013 [33] & $90.9 \%$ & TT (5)/Healthy (5) & Ankle Prosthesis \\
\hline Moon et al. 2019 [34] & $33.3 \%$ & Healthy (1) & Exoskeleton \\
\hline Pew et al. 2017 [35] & $66.7 \%$ & TT (5) & Ankle Prosthesis \\
\hline Shell et al. 2018 [36] & $70.8 \%$ & TT (3) & Ankle Prosthesis \\
\hline Simon et al. 2017 [37] & $66.7 \%$ & $\mathrm{TF}(6)$ & Ankle Knee Prosthesis \\
\hline Spanias et al. 2014 [38] & $54.2 \%$ & $\mathrm{TF}(4)$ & Ankle Knee Prosthesis \\
\hline Spanias et al. 2015 [39] & $54.2 \%$ & $\mathrm{TF}(6)$ & Ankle Knee Prosthesis \\
\hline Spanias et al. 2016a [40] & $62.5 \%$ & $\mathrm{TF}(8)$ & Ankle Knee Prosthesis \\
\hline Spanias et al. 2016b [8] & $58.3 \%$ & Healthy (2) & Ankle Knee Prosthesis \\
\hline Spanias et al. 2017 [41] & $58.3 \%$ & $\mathrm{TF}(3)$ & Ankle Knee Prosthesis \\
\hline Spanias et al. 2018 [42] & $62.5 \%$ & $\mathrm{TF}(8)$ & Ankle Knee Prosthesis \\
\hline Stolyarov et al. 2017 [43] & $79.2 \%$ & $\mathrm{TF}(6)$ & Ankle Knee Prosthesis \\
\hline Su et al. 2019 [44] & $77.3 \%$ & TF (1)/Healthy (10) & Ankle Knee Prosthesis \\
\hline Tkach et al. 2013 [45] & $62.5 \%$ & TT (5) & Ankle Prosthesis \\
\hline Wang et al. 2013 [46] & $66.7 \%$ & TT (1) & Ankle Prosthesis \\
\hline Wang et al. 2018 [47] & $79.2 \%$ & Healthy (22) & Exoskeleton \\
\hline Woodward et al. 2016 [48] & $91.7 \%$ & $\mathrm{TF}(6)$ & Ankle Knee Prosthesis \\
\hline Xu et al. 2018 [49] & $75.0 \%$ & TT (3) & Ankle Prosthesis \\
\hline Young et al. 2013a [50] & $66.7 \%$ & $\mathrm{TF}(4)$ & Ankle Knee Prosthesis \\
\hline Young et al. 2013b [51] & $79.2 \%$ & $\mathrm{TF}(6)$ & Ankle Knee Prosthesis \\
\hline Young et al. 2013c [52] & $62.5 \%$ & $\mathrm{TF}(4)$ & Ankle Knee Prosthesis \\
\hline Young et al. 2014a [53] & $66.7 \%$ & $\mathrm{TF}(6)$ & Ankle Knee Prosthesis \\
\hline Young et al. 2014b [54] & $75.0 \%$ & $\mathrm{TF}(8)$ & Ankle Knee Prosthesis \\
\hline Young et al. 2016 [55] & $75.0 \%$ & $\mathrm{TF}(8)$ & Ankle Knee Prosthesis \\
\hline Zhang et al. 2011 [56] & $70.8 \%$ & TF (1)/Healthy (1) & Ankle Knee Prosthesis \\
\hline Zhang et al. 2013 [57] & $66.7 \%$ & $\mathrm{TF}(4)$ & Ankle Knee Prosthesis \\
\hline Zhang et al. 2019 [58] & $63.6 \%$ & TF (3)/Healthy (6) & Ankle Knee Prosthesis \\
\hline Zhang et al. 2019 [59] & $59.1 \%$ & TF (3)/Healthy (6) & Ankle Knee Prosthesis \\
\hline Zhang et al. 2012 [60] & $62.5 \%$ & Healthy (1) & Ankle Knee Prosthesis \\
\hline Zheng et al. 2013 [61] & $86.4 \%$ & $\mathrm{TT}(1)$ & Ankle Prosthesis \\
\hline Zheng et al. 2014 [62] & $86.4 \%$ & TT (6) & Ankle Prosthesis \\
\hline Zheng et al. 2016 [63] & $75.0 \%$ & TT (6) & Ankle Prosthesis \\
\hline Zheng et al. 2019 [64] & $54.2 \%$ & TT (6) & Ankle Prosthesis \\
\hline Zhou et al. 2019 [65] & $54.2 \%$ & Healthy (3) & Exoskeleton \\
\hline
\end{tabular}

$\mathrm{TT}=$ Volunteer with a unilateral transtibial amputation, $\mathrm{TF}=$ Volunteer with a unilateral transfemoral amputation, $\mathrm{N}=$ Number of recruited volunteers.

\subsection{Extracted Elements of the Included Studies}

In this section, we summarize some of the key aspects of the extracted elements of the included studies.

\subsubsection{Type of Assistive Device and Related Population}

The type of assistive device used in each study and the related population are detailed in Table 1. Four types of devices were used in the included studies: prostheses for transfemoral amputation (i.e., above-knee prostheses), prostheses for transtibial amputation (i.e., below-knee prostheses), exoskeletons and orthoses.

- Above-knee prostheses. This was the largest group among the published studies $(\mathrm{N}=32)$. Among these thirty-two studies, the recruited population were either patients with unilateral 
transfemoral amputation or knee disarticulation $(\mathrm{N}=19)$. There were healthy volunteers and patients with transfemoral amputation or knee disarticulation $(\mathrm{N}=10)$. Finally, there were healthy volunteers wearing an above-knee prosthesis with an L-shape adaptor $(\mathrm{N}=3)$.

- Below-knee prosthesis. This was the second largest group in this review $(\mathrm{N}=18)$. Among those eighteen studies, the recruited population were either patients with unilateral transtibial amputation $(\mathrm{N}=13)$ or healthy volunteers or patients with unilateral transtibial amputation $(\mathrm{N}=5)$.

- Exoskeletons and orthoses. This constituted the smallest group in this review $(\mathrm{N}=6$ and $\mathrm{N}=2$ respectively). Among those eight studies, the recruited population was always healthy volunteers wearing the assistive device.

\subsubsection{Locomotion Activities and Walking Speed}

The locomotion activities and walking speed investigated in each study are reported in Table 2.

The most representative experimental protocol investigated level ground walking along with stair and ramp ascent/descent activities $(\mathrm{N}=43)$. Secondly, in some studies, level ground walking was investigated only with stair ascent and/or descent activities $(\mathrm{N}=13)$. Among those fifty-six $(43+13)$ studies, additional activities were also considered such as obstacle clearance $(\mathrm{N}=6)$, turning $(\mathrm{N}=2)$ or squatting $(\mathrm{N}=1 / 58)$ for 'dynamic' activities and standing $(\mathrm{N}=23 / 58)$ or sitting $(\mathrm{N}=6 / 58)$ for static activities. The remaining two papers investigated level ground walking with cross slope walking $(\mathrm{N}=1)$ and level ground walking with turning $(\mathrm{N}=1)$.

In most studies, the walking speed was not provided $(\mathrm{N}=33)$. One can assume that the volunteers walked at a self-selected speed in these thirty-three studies. Next, the volunteers were asked to walk at a self-selected speed in seventeen studies $(\mathrm{N}=17)$. Finally, a small number of studies investigated different walking speeds: volunteers were asked to walk either at self-selected speed or at a slower or faster pace for different locomotion activities $(\mathrm{N}=6)$. In the two remaining studies, recruited volunteers were asked to walk at a predefined speed of $0.7 \mathrm{~m} / \mathrm{s}(\mathrm{N}=2)$. 
Table 2. Sensors used for recognition and/or prediction of the locomotion activities investigated in the included studies.

\begin{tabular}{|c|c|c|c|c|c|c|c|}
\hline Article & Locomotion Activities & Critical Timing & Speed & Sensors & Axes $\times$ Sensors & Offline/Online & Recognition/Prediction \\
\hline Ai et al. 2017 [9] & LW, SA, SD, ST, SQ & NP & NP & $\begin{array}{l}\text { EMG } \\
\text { IMU }\end{array}$ & $\begin{array}{l}1 \times 4 \\
3(\mathrm{~A}) \times 1\end{array}$ & Off & $\mathrm{R}$ \\
\hline Beil et al. 2018 [10] & LW, SA, SD, Turns, ST & NA & SSS & $\begin{array}{l}\text { Force Sensors } \\
\text { IMU }\end{array}$ & $\begin{array}{l}3 \times 7 \\
6(\mathrm{~A}, \alpha) \times 3\end{array}$ & Off & $\mathrm{R}$ \\
\hline Chen et al. 2013 [11] & LW, SA, SD, OBS, ST, SIT & NA & NP & $\begin{array}{l}\text { Capacitive } \\
\text { Pressure }\end{array}$ & $\begin{array}{l}1 \times 10 \\
2 \times 1\end{array}$ & Off & $\mathrm{R}$ \\
\hline Chen et al. 2014 [12] & LW, SA, SD, RA, RD & 3 & NP & $\begin{array}{l}\text { IMU } \\
\text { Pressure }\end{array}$ & $\begin{array}{l}9(\mathrm{~A}, \mathrm{G}, \alpha) \times 2 \\
4 \times 2\end{array}$ & Off & $\mathrm{R}$ \\
\hline Chen et al. 2015 [13] & LW, SA, SD, OBS, ST, SIT & NA & SSS & Pressure & $4 \times 1$ & Off & $\mathrm{R}$ \\
\hline Du et al. 2012 [14] & LW, SA, SD, RA, RD & 2 & NP & $\begin{array}{l}\text { EMG } \\
\text { Load cell }\end{array}$ & $\begin{array}{l}1 \times 9 \\
6 \times 1 \\
\end{array}$ & Off & $P$ \\
\hline Du et al. 2013 [15] & LW, SA, SD, RA, RD & NP & NP & $\begin{array}{l}\text { EMG } \\
\text { Load cell }\end{array}$ & $\begin{array}{l}1 \times 7 \\
6 \times 1\end{array}$ & Off & $\mathrm{P}$ \\
\hline Feng et al. 2019 [16] & LW, SA, SD, RA, RD & NA & $\mathrm{NP}$ & $\begin{array}{l}\text { Load cell } \\
\text { Angle Sensor }\end{array}$ & $\begin{array}{l}\mathrm{NP} \\
1 \times 1\end{array}$ & Off & $\mathrm{R}$ \\
\hline Godiyal et al. 2018 [17] & LW, SA, SD, RA, RD & NA & SSS & $\begin{array}{l}\text { FMG } \\
\text { Pressure }\end{array}$ & $\begin{array}{l}1 \times 8 \\
3 \times 1\end{array}$ & Off & $\mathrm{R}$ \\
\hline Gong et al. 2018 [18] & LW, SA, SD, RA, RD, ST & NA & Imposed Speed & IMU & $9(\mathrm{~A}, \mathrm{G}, \alpha) \times 2$ & Off and On & $\mathrm{R}$ \\
\hline Gong et al. 2020 [19] & LW, SA, SD, RA, RD, ST & NA & Imposed Speed & IMU & $9(\mathrm{~A}, \mathrm{G}, \alpha) \times 2$ & Off and On & $\mathrm{R}$ \\
\hline Hernandez et al. 2012 [20] & LW, SA, SD, RA, RD, ST, SIT & NP & NP & $\begin{array}{l}\text { Load cell } \\
\text { EMG }\end{array}$ & $\begin{array}{l}6 \times 1 \\
1 \times 7\end{array}$ & Off & $\mathrm{R}$ \\
\hline Hernandez et al. 2013 [21] & LW, SA, ST & 2 & $\mathrm{NP}$ & $\begin{array}{l}\text { Load cell } \\
\text { EMG }\end{array}$ & $\begin{array}{l}6 \times 1 \\
1 \times 7 \\
\end{array}$ & Off and On & $\mathrm{P}$ \\
\hline Huang et al. 2009 [22] & LW, SA, SD, OBS, Turns, ST & NA & SSS & $\begin{array}{l}\text { EMG } \\
\text { Pressure }\end{array}$ & $\begin{array}{l}1 \times 11 \\
2 \times 1 \\
\end{array}$ & Off & $\mathrm{R}$ \\
\hline Huang et al. 2010 [23] & LW, SA, SD, OBS & 1 & SSS & $\begin{array}{l}\text { EMG } \\
\text { Pressure }\end{array}$ & $\begin{array}{l}1 \times 11 \\
\mathrm{NP}\end{array}$ & Off & $\mathrm{P}$ \\
\hline Huang et al. 2011 [24] & LW, SA, SD, RA, RD, OBS & 2 & SSS & $\begin{array}{l}\text { EMG } \\
\text { Load cell } \\
\text { Pressure }\end{array}$ & $\begin{array}{l}1 \times 11 \\
6 \times 1 \\
\mathrm{NP}\end{array}$ & Off & $\mathrm{P}$ \\
\hline
\end{tabular}


Table 2. Cont.

\begin{tabular}{|c|c|c|c|c|c|c|c|}
\hline Article & Locomotion Activities & Critical Timing & Speed & Sensors & Axes $\times$ Sensors & Offline/Online & Recognition/Prediction \\
\hline Kim et al. 2017 [25] & LW, SA, SD, RA, RD & NA & NP & $\begin{array}{l}\text { Joint angle } \\
\text { IMU } \\
\text { Load cell } \\
\text { Pressure }\end{array}$ & $\begin{array}{l}1 \times 4 \\
3(\alpha) \times 5 \\
1 \times 4 \\
4 \times 1\end{array}$ & Off & $\mathrm{R}$ \\
\hline Liu et al. 2016 [26] & LW, SA, SD, RA, RD & 2 & SSS & $\begin{array}{l}\text { EMG } \\
\text { Load cell } \\
\text { IMU } \\
\text { Laser }\end{array}$ & $\begin{array}{l}1 \times 8 \\
6 \times 1 \\
6(A, G, \alpha) \times 1 \\
1 \times 1\end{array}$ & Off and On & $\mathrm{P}$ \\
\hline Liu et al. 2017 [27] & LW, SA, SD, RA, RD & $\mathrm{NP}$ & NP & $\begin{array}{l}\text { EMG } \\
\text { Load cell }\end{array}$ & $\begin{array}{l}1 \times 7 \\
6 \times 1 \\
\end{array}$ & Off and On & $\mathrm{P}$ \\
\hline Liu et al. 2017 [28] & LW, SA, SD, RA, RD & NA & SSS, SL, F & $\begin{array}{l}\text { IMU } \\
\text { Pressure }\end{array}$ & $\begin{array}{l}4(\mathrm{~A}, \mathrm{G}) \times 1 \\
2 \times 2\end{array}$ & Off & $\mathrm{R}$ \\
\hline Long et al. 2016 [29] & LW, SA, SD, RA, RD & 5 & SSS & $\begin{array}{l}\text { IMU } \\
\text { Pressure }\end{array}$ & $\begin{array}{l}3(\alpha) \times 4 \\
3 \times 2\end{array}$ & Off and On & $\mathrm{P}$ \\
\hline Mai et al. 2011 [30] & LW, SA, SD & NA & SSS, F & Load cell & $1 \times 12$ & Off & $\mathrm{R}$ \\
\hline Mai et al. 2018a [31] & LW, SA, SD, RA, RD, ST & $\mathrm{NP}$ & $\mathrm{NP}$ & IMU & $9(\mathrm{~A}, \mathrm{G}, \alpha) \times 2$ & Off and On & $\mathrm{R}$ \\
\hline Mai et al. 2018b [32] & LW, SA, SD, RA, RD & $\mathrm{NP}$ & $\mathrm{NP}$ & IMU & $8(3 \mathrm{~A}, 3 \mathrm{G}, 2 \alpha) \times 2$ & Off and On & $\mathrm{R}$ \\
\hline Miller et al. 2013 [33] & LW, SA, SD, RA, RD & NA & SSS, (SL, F) for LW & $\begin{array}{l}\text { EMG } \\
\text { Pressure }\end{array}$ & $\begin{array}{l}1 \times 4 \\
2 \times 2\end{array}$ & Off & $\mathrm{R}$ \\
\hline Moon et al. 2019 [34] & LW, SA, SD & NP & NP & $\begin{array}{l}\text { Motor Encoder } \\
\text { Spring length }\end{array}$ & $\begin{array}{l}1 \times 1 \\
1 \times 1 \\
\end{array}$ & Off and On & $\mathrm{R}$ \\
\hline Pew et al. 2017 [35] & LW, Turns & $\mathrm{NP}$ & SSS & Load cell & $6 \times 1$ & Off & $\mathrm{P}$ \\
\hline Shell et al. 2018 [36] & LW, cross-slope & $\mathrm{NP}$ & $\mathrm{NP}$ & IMU & $5(3 \mathrm{~A}, 2 \mathrm{G}) \times 1$ & Off & $\mathrm{R}$ \\
\hline Simon et al. 2017 [37] & LW, SA, SD, RA, RD, ST & 3 & SSS, (SL, F) for LW & $\begin{array}{l}\text { Joint Angle } \\
\text { Joint Velocity } \\
\text { Motor Current } \\
\text { IMU } \\
\text { Load cell }\end{array}$ & $\begin{array}{l}1 \times 2 \\
1 \times 2 \\
1 \times 2 \\
6(A, G, \alpha) \times 1 \\
6 \times 1\end{array}$ & Off & $\mathrm{P}$ \\
\hline Spanias et al. 2014 [38] & LW, SA, SD, RA, RD & 2 & NP & $\begin{array}{l}\text { Joint Angle } \\
\text { Joint Velocity } \\
\text { Motor Current } \\
\text { IMU } \\
\text { Load cell } \\
\text { EMG }\end{array}$ & $\begin{array}{l}1 \times 2 \\
1 \times 2 \\
1 \times 2 \\
6(A, G, \alpha) \times 1 \\
1 \times 1 \\
1 \times 9\end{array}$ & Off & $P$ and $R$ \\
\hline
\end{tabular}


Table 2. Cont.

\begin{tabular}{|c|c|c|c|c|c|c|c|}
\hline Article & Locomotion Activities & Critical Timing & Speed & Sensors & Axes $\times$ Sensors & Offline/Online & Recognition/Prediction \\
\hline Spanias et al. 2015 [39] & LW, SA, SD, RA, RD & 2 & SSS, SL, F & $\begin{array}{l}\text { Joint Angle } \\
\text { Joint Velocity } \\
\text { Motor Current } \\
\text { IMU } \\
\text { Load cell } \\
\text { EMG }\end{array}$ & $\begin{array}{l}1 \times 2 \\
1 \times 2 \\
1 \times 2 \\
8(3 \mathrm{~A}, 3 \mathrm{G}, 2 \alpha) \times 1 \\
6 \times 1 \\
1 \times 4\end{array}$ & Off & $\mathrm{P}$ \\
\hline Spanias et al. 2016a [40] & LW, SA, SD, RA, RD & 2 & NP & $\begin{array}{l}\text { Joint Angle } \\
\text { Joint Velocity } \\
\text { Motor Current } \\
\text { IMU } \\
\text { Load cell } \\
\text { EMG }\end{array}$ & $\begin{array}{l}1 \times 2 \\
1 \times 2 \\
1 \times 2 \\
6(\mathrm{~A}, \mathrm{G}, \alpha) \times 1 \\
1 \times 1 \\
1 \times 9\end{array}$ & Off & $\mathrm{P}$ \\
\hline Spanias et al. 2016b [8] & LW, SA, SD, RA, RD, ST & 3 & NP & $\begin{array}{l}\text { Joint Angle } \\
\text { Joint Velocity } \\
\text { Motor Current } \\
\text { IMU } \\
\text { Load cell }\end{array}$ & $\begin{array}{l}1 \times 2 \\
1 \times 2 \\
1 \times 2 \\
10(3 \mathrm{~A}, 3 \mathrm{G}, 4 \alpha) \times 1 \\
6 \times 1\end{array}$ & Off and On & $P$ and $R$ \\
\hline Spanias et al. 2017 [41] & LW, SA, SD, RA, RD, ST & 3 & NP & $\begin{array}{l}\text { Joint Angle } \\
\text { Joint Velocity } \\
\text { Motor Current } \\
\text { IMU } \\
\text { Load cell }\end{array}$ & $\begin{array}{l}1 \times 2 \\
1 \times 2 \\
1 \times 2 \\
10(3 \mathrm{~A}, 3 \mathrm{G}, 4 \alpha) \times 1 \\
6 \times 1\end{array}$ & Off and On & $P$ and $R$ \\
\hline Spanias et al. 2018 [42] & LW, SA, SD, RA, RD, ST & 3 & NP & $\begin{array}{l}\text { Joint Angle } \\
\text { Joint Velocity } \\
\text { Motor Current } \\
\text { IMU } \\
\text { Load cell } \\
\text { EMG }\end{array}$ & $\begin{array}{l}1 \times 2 \\
1 \times 2 \\
1 \times 2 \\
10(3 \mathrm{~A}, 3 \mathrm{G}, 4 \alpha) \times 1 \\
6 \times 1 \\
1 \times 8\end{array}$ & Off and On & $P$ and $R$ \\
\hline Stolyarov et al. 2017 [43] & LW, SA, SD, RA, RD & NP & SSS & IMU & $6(\mathrm{~A}, \mathrm{G}) \times 1$ & Off & $\mathrm{P}$ \\
\hline Su et al. 2019 [44] & LW, SA, SD, RA, RD & NP & SSS & IMU & $6(\mathrm{~A}, \mathrm{G}) \times 3$ & Off & $\mathrm{R}$ \\
\hline Tkach et al. 2013 [45] & LW, SA, SD, RA, RD & NP & SSS & $\begin{array}{l}\text { IMU } \\
\text { Joint Angle } \\
\text { Joint Velocity } \\
\text { Joint Current } \\
\text { EMG }\end{array}$ & $\begin{array}{l}3(\mathrm{~A}) \times 1 \\
1 \times 1 \\
1 \times 1 \\
1 \times 1 \\
1 \times 4\end{array}$ & Off & $\mathrm{R}$ \\
\hline
\end{tabular}


Table 2. Cont

\begin{tabular}{|c|c|c|c|c|c|c|c|}
\hline Article & Locomotion Activities & Critical Timing & Speed & Sensors & Axes $\times$ Sensors & Offline/Online & Recognition/Prediction \\
\hline Wang et al. 2013 [46] & LW, SA, SD, ST, SIT & NA & $\mathrm{NP}$ & Pressure & $4 \times 1$ & Off & $\mathrm{R}$ \\
\hline Wang et al. 2018 [47] & LW, SA, SD, ST, SIT & 2 & $\mathrm{NP}$ & Joint Angles & $1 \times 6$ & Off and On & $\mathrm{P}$ \\
\hline Woodward et al. 2016 [48] & LW, SA, SD, RA, RD & NP & NP & $\begin{array}{l}\text { IMU } \\
\text { Joint Angle } \\
\text { Joint Velocity } \\
\text { Joint Current } \\
\text { Load cell }\end{array}$ & $\begin{array}{l}7(3 \mathrm{~A}, 3 \mathrm{G}, 1 \alpha) \times 1 \\
1 \times 2 \\
1 \times 2 \\
1 \times 2 \\
6 \times 1\end{array}$ & Off & $\mathrm{P}$ \\
\hline Xu et al. 2018 [49] & LW, SA, SD, RA, RD, ST & 4 & NP & $\begin{array}{l}\text { IMU } \\
\text { Load cell }\end{array}$ & $\begin{array}{l}9(\mathrm{~A}, \mathrm{G}, \alpha) \times 1 \\
1 \times 1\end{array}$ & Off and On & $\mathrm{P}$ \\
\hline Young et al. 2013a [50] & LW, SA, SD, RA, RD & 2 & NP & $\begin{array}{l}\text { IMU } \\
\text { Joint Angle } \\
\text { Joint Velocity } \\
\text { Joint Current } \\
\text { Load cell } \\
\text { EMG }\end{array}$ & $\begin{array}{l}6(\mathrm{~A}, \mathrm{G}) \times 1 \\
1 \times 2 \\
1 \times 2 \\
1 \times 2 \\
1 \times 1 \\
1 \times 9\end{array}$ & Off & $\mathrm{P}$ \\
\hline Young et al. 2013b [51] & LW, SA, SD, RA, RD & 2 & $\mathrm{NP}$ & $\begin{array}{l}\text { IMU } \\
\text { Joint Angle } \\
\text { Joint Velocity } \\
\text { Joint Current } \\
\text { Load cell }\end{array}$ & $\begin{array}{l}6(\mathrm{~A}, \mathrm{G}) \times 1 \\
1 \times 2 \\
1 \times 2 \\
1 \times 2 \\
1 \times 1\end{array}$ & Off & $\mathrm{P}$ \\
\hline Young et al. 2013c [52] & LW, SA, SD, RA, RD & 2 & NP & $\begin{array}{l}\text { IMU } \\
\text { Joint Angle } \\
\text { Joint Velocity } \\
\text { Joint Current } \\
\text { Load cell } \\
\text { EMG }\end{array}$ & $\begin{array}{l}6(\mathrm{~A}, \mathrm{G}) \times 1 \\
1 \times 2 \\
1 \times 2 \\
1 \times 2 \\
1 \times 1 \\
1 \times 7\end{array}$ & Off & $\mathrm{P}$ \\
\hline Young et al. 2014a [53] & LW, SA, SD, RA, RD & 2 & SSS & $\begin{array}{l}\text { IMU } \\
\text { Joint Angle } \\
\text { Joint Velocity } \\
\text { Joint Current } \\
\text { Load cell }\end{array}$ & $\begin{array}{l}6(\mathrm{~A}, \mathrm{G}) \times 1 \\
1 \times 2 \\
1 \times 2 \\
1 \times 2 \\
1 \times 1\end{array}$ & Off & $\mathrm{P}$ \\
\hline Young et al. 2014b [54] & LW, SA, SD, RA, RD & 2 & SSS, (SL, F) for LW & $\begin{array}{l}\text { IMU } \\
\text { Joint Angle } \\
\text { Joint Velocity } \\
\text { Joint Current } \\
\text { Load cell } \\
\text { EMG }\end{array}$ & $\begin{array}{l}6(\mathrm{~A}, \mathrm{G}) \times 1 \\
1 \times 2 \\
1 \times 2 \\
1 \times 2 \\
1 \times 1 \\
1 \times 9\end{array}$ & Off & $\mathrm{P}$ \\
\hline
\end{tabular}


Table 2. Cont

\begin{tabular}{|c|c|c|c|c|c|c|c|}
\hline Article & Locomotion Activities & Critical Timing & Speed & Sensors & Axes $\times$ Sensors & Offline/Online & Recognition/Prediction \\
\hline Young et al. 2016 [55] & LW, SA, SD, RA, RD & 2 & SSS & $\begin{array}{l}\text { IMU } \\
\text { Joint Angle } \\
\text { Joint Velocity } \\
\text { Joint Current } \\
\text { Load cell }\end{array}$ & $\begin{array}{l}6(\mathrm{~A}, \mathrm{G}) \times 1 \\
1 \times 2 \\
1 \times 2 \\
1 \times 2 \\
1 \times 1\end{array}$ & Off & $\mathrm{P}$ \\
\hline Zhang et al. 2011 [56] & LW, SA, SD, RA, RD & 2 & NP & $\begin{array}{l}\text { Load cell } \\
\text { EMG }\end{array}$ & $\begin{array}{l}6 \times 1 \\
1 \times 11\end{array}$ & Off and On & $\mathrm{P}$ \\
\hline Zhang et al. 2013 [57] & LW, SA, SD, RA, RD, ST, SIT & NP & NP & $\begin{array}{l}\text { IMU } \\
\text { Load cell } \\
\text { EMG }\end{array}$ & $\begin{array}{l}6(\mathrm{~A}, \mathrm{G}) \times 2 \\
6 \times 1 \\
1 \times 8\end{array}$ & Off and On & $P$ \\
\hline Zhang et al. 2019 [58] & LW, SA, SD, RA, RD & NP & NP & $\begin{array}{l}\text { Depth Camera } \\
\text { IMU }\end{array}$ & $\begin{array}{l}224 \times 171 \\
3(\alpha) \times 1\end{array}$ & Off & $\mathrm{P}$ \\
\hline Zhang et al. 2019 [59] & LW, SA, SD, RA, RD & NP & NP & $\begin{array}{l}\text { Depth Camera } \\
\text { IMU }\end{array}$ & $\begin{array}{l}224 \times 171 \\
3(\alpha) \times 1 \\
\end{array}$ & Off & $\mathrm{P}$ \\
\hline Zhang et al. 2012 [60] & $\mathrm{LW}, \mathrm{SA}, \mathrm{SD}, \mathrm{ST}$ & 2 & NP & $\begin{array}{l}\text { IMU } \\
\text { Laser } \\
\text { Load cell } \\
\text { EMG }\end{array}$ & $\begin{array}{l}6(\mathrm{~A}, \mathrm{G}) \times 1 \\
1 \times 1 \\
6 \times 1 \\
1 \times 7\end{array}$ & Off and On & $\mathrm{P}$ \\
\hline Zheng et al. 2013 [61] & $\begin{array}{l}\text { LW, SA, SD, RA, RD, OBS, } \\
\text { ST }\end{array}$ & NA & SSS & $\begin{array}{l}\text { Capacitive } \\
\text { Pressure }\end{array}$ & $\begin{array}{l}1 \times 7 \\
3 \times 1 \\
\end{array}$ & Off & $\mathrm{R}$ \\
\hline Zheng et al. 2014 [62] & LW, SA, SD, RA, RD, ST & NA & SSS & $\begin{array}{l}\text { Capacitive } \\
\text { Pressure }\end{array}$ & $\begin{array}{l}1 \times 6 \\
3 \times 1\end{array}$ & Off & $\mathrm{R}$ \\
\hline Zheng et al. 2016 [63] & LW, SA, SD, RA, RD, ST & NP & SSS & $\begin{array}{l}\text { IMU } \\
\text { Load cell } \\
\text { Joint angle } \\
\text { Pressure } \\
\text { Capacitive }\end{array}$ & $\begin{array}{l}8(3 \mathrm{~A}, 3 \mathrm{G}, 2 \alpha) \times 2 \\
1 \times 1 \\
1 \times 1 \\
4 \times 1 \\
1 \times 6\end{array}$ & Off & $P$ \\
\hline
\end{tabular}


Table 2. Cont.

\begin{tabular}{|c|c|c|c|c|c|c|c|}
\hline Article & Locomotion Activities & Critical Timing & Speed & Sensors & Axes $\times$ Sensors & Offline/Online & Recognition/Prediction \\
\hline Zheng et al. 2019 [64] & LW, SA, SD, RA, RD, ST & NP & $\mathrm{NP}$ & $\begin{array}{l}\text { IMU } \\
\text { Load cell } \\
\text { Joint angle } \\
\text { Pressure }\end{array}$ & $\begin{array}{l}8(3 \mathrm{~A}, 3 \mathrm{G}, 2 \alpha) \times 2 \\
1 \times 1 \\
1 \times 1 \\
4 \times 1\end{array}$ & Off & $\mathrm{P}$ \\
\hline Zhou et al. 2019 [65] & LW, SA, SD & 3 & NP & $\begin{array}{l}\text { IMU } \\
\text { Load cell } \\
\text { Joint angle }\end{array}$ & $\begin{array}{l}9(A, G, \alpha) \times 2 \\
1 \times 2 \\
1 \times 1\end{array}$ & Off and On & $\mathrm{P}$ \\
\hline
\end{tabular}

Locomotion Activities: LW = Level-ground Walking, SA = Stairs Ascent, SD = Stairs Descent, RA = Ramp Ascent, RD = Ramp Descent, ST = Standing, SIT = Sitting, SQ = Squatting, OBS = Obstacle clearance. Critical Timing: NP = Not Provided, NA = Not Applicable, $1=200 \mathrm{~ms}$ before the prosthesis foot off of the ground for all transitions, $2=$ for transitions from level ground walking to any other locomotion mode, the critical timing was defined either at the prosthesis foot off of the ground or at mid-swing and for transitions from any locomotion mode to level ground walking, the critical timing was defined at prosthesis foot contact on level ground walking or at mid-stance, $3=$ at foot off of the previous locomotion mode for all transitions, $4=$ For level ground walking to stairs ascent or stairs descent transitions, the critical timing was defined either at the prosthesis foot off of the ground or at prosthesis foot contact on the stairs. For any other transitions, the critical timing was defined either at the prosthesis foot contact on the new locomotion mode or at the first prosthesis foot off of the new locomotion mode, $5=$ the critical timing occurred at foot contact of the contralateral leg of the exoskeleton. Speed: NP $=$ Not Provided, SSS $=$ Self-Selected Speed, SL $=$ Slow, $\mathrm{F}=$ Fast, (SL, F) for LW = Slower and faster paces tested only for level-ground walking. Sensors: EMG = ElectroMyoGraphs, IMU = Inertial Motion Unit, FMG = Force MyoGraph. Axes $\times$ Sensors: The number of measurement axes and the number of sensors is reported. For IMUs, the signals used are specified with $\mathrm{A}=\mathrm{Accelerometer}, \mathrm{G}=\mathrm{Gyroscope}, \alpha=\mathrm{Inclination}$.

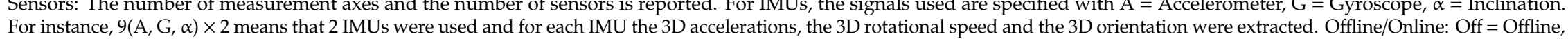
For instance, $9(\mathrm{~A}, \mathrm{G}, \alpha) \times 2$ means that $2 \mathrm{IMUs}$ were used and for each IMU
On $=$ Online. Recognition/Prediction: $\mathrm{R}=$ Recognition, $\mathrm{P}=$ Prediction. 


\subsubsection{Identifying the Critical Timing}

The Critical Timings used in each study are provided in Table 2.

Among the studies focusing on ankle-knee or ankle-foot prostheses $(\mathrm{N}=50)$, most investigated the transitions between locomotion modes $(\mathrm{N}=39)$. Several definitions of critical timing were used. We describe these definitions below:

Firstly, a study ( $\mathrm{N}=1)$ conducted by Huang et al. [23] in 2010 defined the critical timing as $200 \mathrm{~ms}$ before the prosthesis foot off of the ground for all transitions. Figure 2 illustrates the critical timing used in Huang et al. [23] for both level ground walking to stair ascent and stair descent to level ground walking transitions.

Secondly, some studies ( $\mathrm{N}=15)$ (in Huang et al. 2011 [24] for example) chose the critical timings at well-defined gait events (e.g., Foot-Off and Foot Contact): for transitions from level ground walking to any other locomotion mode, the critical timing was defined at the prosthesis foot off of the ground and for transitions from any locomotion mode to level ground walking, the critical timing was defined at prosthesis foot contact on level ground.

Thirdly, some studies ( $\mathrm{N}=5$ ) (in Spanias et al. [42] for example) attempted to delay the critical timing in order to improve the locomotion mode prediction. Here, for transitions from level ground walking to any other locomotion mode, the critical timing was defined $90 \mathrm{~ms}$ after a gait event, such as the prosthesis foot off, mid-swing, prosthesis foot contact or mid-stance.

Finally, in a recent study $(\mathrm{N}=1)$ conducted by $\mathrm{Xu}$ et al. [49] in 2018 defined the definitions of critical timings were altered based on the transition type and on the transitioning leg. As a result, the critical timing was delayed when the amputated leg was the leading leg for the transition. For level ground walking to stair ascent or stairs descent transitions, the critical timing was defined either at the last prosthesis foot off of the ground or at the first prosthesis foot contact on the stairs. For any other transitions, the critical timing was defined either at the first prosthesis foot contact on the new locomotion mode or at the first prosthesis foot off of the new locomotion mode.

The other studies did not investigate the transitions $(\mathrm{N}=11)$ or did not report the critical timings used in the study $(\mathrm{N}=17)$.

Among the studies focusing on orthoses or exoskeletons $(\mathrm{N}=8)$, only three studies investigated the transitions between locomotion modes. In Long et al. [29], the critical timing occurred at foot contact of the contralateral leg of the exoskeleton. In Wang et al. [47], the critical timing occurred at foot contact of the ipsilateral leg in the new locomotion mode. Finally, in Zhou et al. [65], the critical timing occurred at mid-swing when the leg wearing the exoskeleton led the transition. It occurred at the last foot off of the ground for transitions from level ground to any other locomotion mode and finally for transitions from any locomotion mode to level ground walking it was at the first foot off of the ground. The remaining studies either did not investigate the transitions $(\mathrm{N}=4)$ or did not report the critical timings used in the study $(\mathrm{N}=1)$. 


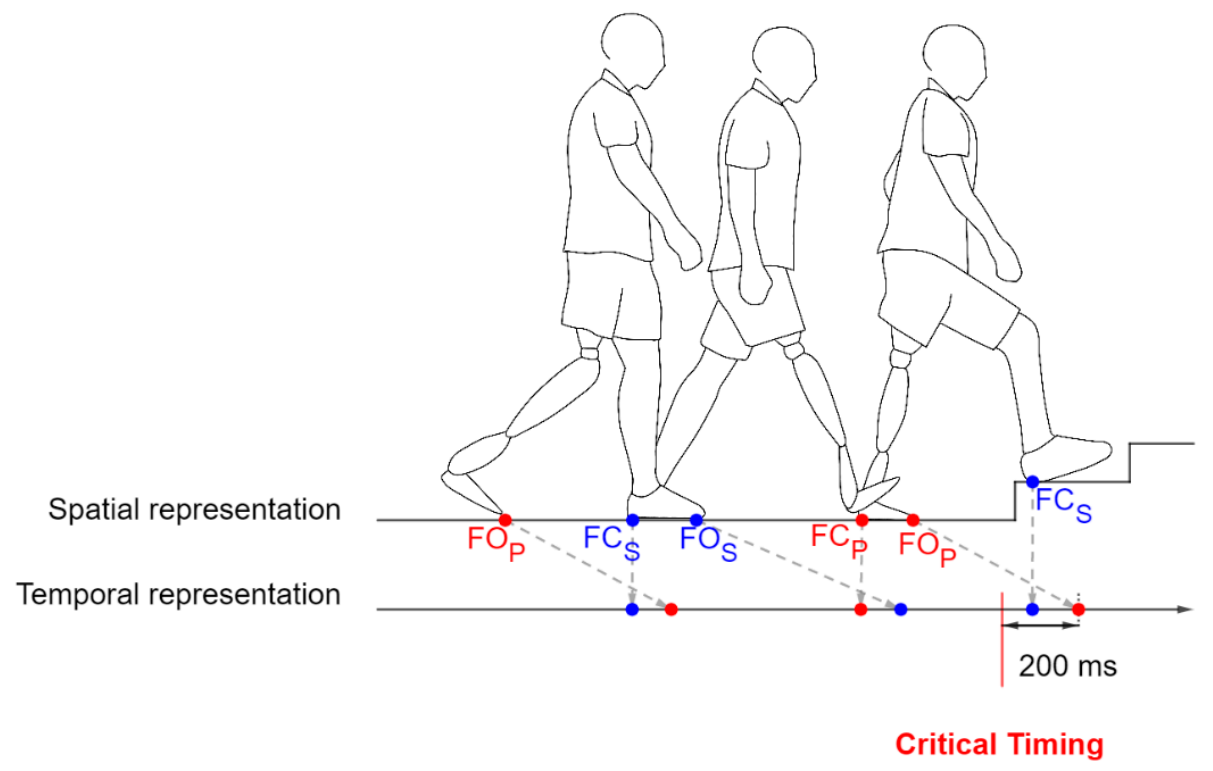

A-Level walking to stair ascent

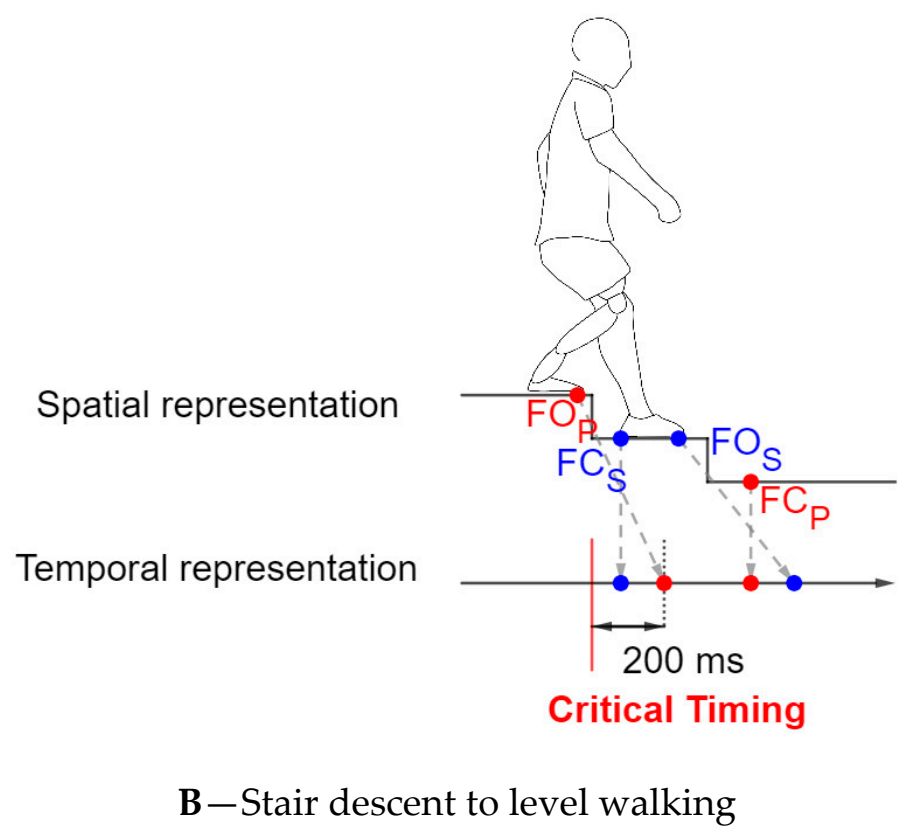

Figure 2. Example of the critical timings used in Huang et al. [23].

Panel A represents a patient with amputation in his transition from level walking to stair ascent. The superior part of this panel is a spatial representation of the patient motion. The line below is the temporal representation of the foot contact events. A dashed line maps the spatial representation to the temporal representation. For the spatial representation, the points refer to the spatial coordinates where the foot will hit/leave the ground. The temporal axis details the Foot Contact (FC) and Foot Off (FO) gait events for both sides. Critical timing is defined $200 \mathrm{~ms}$ prior to the prosthesis Foot Off event according to the Huang et al. Study [23]. The blue points are associated with the sound leg (Index S) and the red points are associated with the prosthesis side (index P). The panel B uses the same representation for patient from level walking to stair descent. 
3.3.4. Online/Offline Implementation of Machine Learning Algorithm for Prediction of the Upcoming Locomotion Mode or Recognition of the Current Locomotion Mode

Information regarding the type of implementation of the Machine Learning algorithms is provided in Table 2: recognition and/or prediction algorithm and online and/or offline implementation.

The Machine Learning algorithms developed in the studies included in this systematic review were designed either to predict the upcoming locomotion mode $(\mathrm{N}=30)$ or to recognize the current locomotion mode $(\mathrm{N}=24)$. Some studies developed a Locomotion Mode Recognition system with adaptive strategies $(\mathrm{N}=4)$. A forward predictor identified the upcoming locomotion mode while a backward estimator recognized the current locomotion mode. The backward estimator was used to label new data and the forward predictor could be updated with these newly labeled data.

Most of algorithms were trained and evaluated offline $(\mathrm{N}=40)$ with a few which were trained offline and evaluated online $(\mathrm{N}=18)$.

\subsubsection{Data Type and Sensors Used}

The details concerning the sensors used in the studies are provided in Table 2.

Sensors used in the included studies were of four types:

- Kinematic data were measured with sensors such as Inertial Motion Units (IMUs) $(\mathrm{N}=36$ ), or angle encoders $(\mathrm{N}=21)$.

- Kinetic data such as interaction force between the device and the user were measured with load cell $(\mathrm{N}=31)$. Ground reaction force was measured with foot insoles $(\mathrm{N}=17)$ and torque at the joint was measured with motor current sensors $(\mathrm{N}=14)$ or by measuring the length of a spring $(\mathrm{N}=1)$.

- Physiological data were measured with sensors such as Electromyographs (EMG) $(N=21)$, Capacitive Sensing Systems (CSS) $(\mathrm{N}=4)$ or Forcemyographs (FMG) $(\mathrm{N}=1)$.

- Extrinsic data such as the distance between the user and an upcoming obstacle were measured with laser distance meters $(\mathrm{N}=2)$ or with depth cameras $(\mathrm{N}=2)$.

\subsubsection{Analysis Windows}

The details concerning the analysis windows used in each study are provided in Table 3.

Three types of analysis windows can be distinguished: sliding $(\mathrm{N}=30)$, unique $(\mathrm{N}=7)$ or multiple $(\mathrm{N}=19)$ windows. The first method consisted of using a sliding analysis window by defining a window length and a window increment. The windows can therefore overlap. For the unique and multiple methods, the analysis window(s) was (were) defined either by a starting or ending point and a fixed window length $(\mathrm{N}=21)$ or by both end points with a variable window length $(\mathrm{N}=5)$. The remaining studies $(\mathrm{N}=2)$ did not provide any information concerning analysis windows. 
Table 3. Preprocessing techniques, Machine Learning algorithms and reported accuracies of the included studies. The details of the preprocessing techniques (windows and features) and the machine learning algorithms used in each study are reported along with the corresponding accuracy. If several configurations were tested, only the optimal configuration is reported.

\begin{tabular}{|c|c|c|c|c|c|c|c|}
\hline \multirow{2}{*}{ Article } & \multicolumn{3}{|c|}{ Analysis Windows } & \multirow{2}{*}{ Sensors } & \multirow{2}{*}{ Features } & \multirow{2}{*}{ Algorithm } & \multirow{2}{*}{ Accuracy } \\
\hline & Type & Number & Length & & & & \\
\hline Ai et al. 2017 [9] & Sliding & NA & 250 & $\begin{array}{l}\text { EMG } \\
\text { Mech }\end{array}$ & $\begin{array}{l}\text { WT } \\
\text { DTW }\end{array}$ & SVM & 97.9 \\
\hline Beil et al. 2018 [10] & Sliding & NA & 300 & Mech & Raw data & HMM & 92.8 \\
\hline Chen et al. 2013 [11] & Sliding & NA & 150 & Capacitive & $\begin{array}{l}\text { Mean, Max, } \\
\text { Min, RMS }\end{array}$ & LDA & 94.54 \\
\hline Chen et al. 2014 [12] & Sliding & NA & 160 & $\begin{array}{l}\text { Pressure } \\
\text { Mech }\end{array}$ & $\begin{array}{c}\text { Mean, Max, } \\
\text { Min, SD, RMS, } \\
\text { WL, CORR } \\
\text { Mean, Max, } \\
\text { Min, SD, RMS, } \\
\text { WL, ZC, } \\
\text { CORR }\end{array}$ & LR & 98.2 \\
\hline Chen et al. 2015 [13] & Multiple & 4 & 200 & Pressure & $\mathrm{SD}, \mathrm{AR}$ & LDA & 98.4 \\
\hline Du et al. 2012 [14] & Sliding & NA & 150 & $\begin{array}{l}\text { EMG } \\
\text { Mech }\end{array}$ & $\begin{array}{l}\text { MAV, SSC, } \\
\text { WL, ZC } \\
\text { Mean, Max, } \\
\text { Min }\end{array}$ & LDA & 98 \\
\hline Du et al. 2013 [15] & Sliding & NA & 160 & $\begin{array}{l}\text { EMG } \\
\text { Mech }\end{array}$ & $\begin{array}{l}\text { MAV, SSC, } \\
\text { WL, ZC } \\
\text { Mean, Max, } \\
\text { Min }\end{array}$ & EBA & 92.5 \\
\hline Feng et al. 2019 [16] & Unique & 1 & $\begin{array}{l}\text { Gait } \\
\text { Cycle }\end{array}$ & Mech & Raw Data & $\mathrm{CNN}$ & 92.1 \\
\hline Godiyal et al. 2018 [17] & Unique & 1 & Stance & FMG & $\begin{array}{c}\text { Mean, Max, } \\
\text { Min, SD, RMS, } \\
\text { WL, SSC, } \\
\text { MAD }\end{array}$ & LDA & 96.1 \\
\hline Gong et al. 2018 [18] & Sliding & NA & 250 & Mech & $\begin{array}{c}\text { Mean, Max, } \\
\text { Min, SD, MAD }\end{array}$ & ANN & 97.8 \\
\hline Gong et al. 2020 [19] & Sliding & NA & 250 & Mech & $\begin{array}{c}\text { Mean, Max, } \\
\text { Min, SD, MAD }\end{array}$ & ANN & 98.4 \\
\hline Hernandez et al. 2012 [20] & Sliding & NA & 150 & $\begin{array}{l}\text { EMG } \\
\text { Mech }\end{array}$ & $\begin{array}{l}\text { MAV, SSC, } \\
\text { WL, ZC } \\
\text { Mean, Max, } \\
\text { Min }\end{array}$ & SVM & $\mathrm{NP}$ \\
\hline Hernandez et al. 2013 [21] & Sliding & NA & 160 & $\begin{array}{l}\text { EMG } \\
\text { Mech }\end{array}$ & $\begin{array}{l}\text { MAV, SSC, } \\
\text { WL, ZC } \\
\text { Mean, Max, } \\
\text { Min }\end{array}$ & SVM & 99.9 \\
\hline Huang et al. 2009 [22] & Sliding & NA & 140 & EMG & $\begin{array}{l}\text { MAV, SSC, } \\
\text { WL, ZC }\end{array}$ & LDA & 95.5 \\
\hline Huang et al. 2010 [23] & Multiple & 3 & 100 & EMG & $\begin{array}{c}\text { MAV, SSC, } \\
\text { WL, ZC }\end{array}$ & LDA & NR \\
\hline Huang et al. 2011 [24] & Sliding & NA & 150 & $\begin{array}{l}\text { EMG } \\
\text { Mech }\end{array}$ & $\begin{array}{l}\text { MAV, SSC, } \\
\text { WL, ZC } \\
\text { Mean, Max, } \\
\text { Min }\end{array}$ & SVM & 100 \\
\hline Kim et al. 2017 [25] & Unique & 1 & $\begin{array}{c}\text { FC } \\
\text { contro to } \\
\text { FC ipsi }\end{array}$ & Mech & $\begin{array}{l}\text { Custom } \\
\text { values }\end{array}$ & DT & 99.1 \\
\hline Liu et al. 2016 [26] & Sliding & NA & 50 & $\begin{array}{l}\text { EMG } \\
\text { Mech }\end{array}$ & $\begin{array}{l}\text { MAV, SSC, } \\
\text { WL, ZC } \\
\text { Mean, Max, } \\
\text { Min, SD }\end{array}$ & LDA & $\sim 98$ \\
\hline
\end{tabular}


Table 3. Cont.

\begin{tabular}{|c|c|c|c|c|c|c|c|}
\hline \multirow{2}{*}{ Article } & \multicolumn{3}{|c|}{ Analysis Windows } & \multirow{2}{*}{ Sensors } & \multirow{2}{*}{ Features } & \multirow{2}{*}{ Algorithm } & \multirow{2}{*}{ Accuracy } \\
\hline & Type & Number & Length & & & & \\
\hline Liu et al. 2017 [27] & Sliding & NA & 160 & $\begin{array}{l}\text { EMG } \\
\text { Mech }\end{array}$ & $\begin{array}{c}\text { MAV, SSC, } \\
\text { WL, ZC } \\
\text { Mean, Max, } \\
\text { Min, SD }\end{array}$ & EBA/LIFT & 94.3 \\
\hline Liu et al. 2017 [28] & Unique & 1 & 800 & Mech & ICC & HMM & 95.8 \\
\hline Long et al. 2016 [29] & $\mathrm{NP}$ & $\mathrm{NP}$ & $\mathrm{NP}$ & Mech & WT & SVM & 98.4 \\
\hline Mai et al. 2011 [30] & Unique & 1 & Stance & Mech & $\begin{array}{c}\text { Mean, Force } \\
\text { Changing } \\
\text { Rate, Force } \\
\text { Ratio }\end{array}$ & ANN & 98.5 \\
\hline Mai et al. 2018a [31] & Sliding & NA & 100 & Mech & $\begin{array}{l}\text { Mean, Max, } \\
\text { Min, SD, Diff }\end{array}$ & SVM & NP \\
\hline Mai et al. 2018b [32] & Sliding & NA & $100 \mathrm{pts}$ & Mech & $\begin{array}{l}\text { Mean, Max, } \\
\text { Min, SD, Diff }\end{array}$ & SVM & 99.4 \\
\hline Miller et al. 2013 [33] & Multiple & 3 & $200 / 300 / 100$ & EMG & $\begin{array}{c}\text { MAV, SSC, } \\
\text { WL, ZC, SD }\end{array}$ & SVM & 98.5 \\
\hline Moon et al. 2019 [34] & Sliding & NA & NP & Mech & Raw data & ANN & NP \\
\hline Pew et al. 2017 [35] & NP & $\mathrm{NP}$ & NP & Mech & $\mathrm{NP}$ & KNN & 93.8 \\
\hline Shell et al. 2018 [36] & Sliding & NA & 150 & Mech & $\begin{array}{l}\text { Mean, SD, } \\
\text { Max, Min }\end{array}$ & LDA & 78 \\
\hline Simon et al. 2017 [37] & Multiple & 2 & 300 & Mech & WT & DBN & 99.6 \\
\hline Spanias et al. 2014 [38] & Multiple & 2 & 300 & $\begin{array}{l}\text { EMG } \\
\text { Mech }\end{array}$ & $\begin{array}{c}\text { MAV, SSC, } \\
\text { WL, ZC, AR } \\
\text { Mean, Max, } \\
\text { Min, SD, IV, } \\
\text { FV }\end{array}$ & LDA & $\sim 96$ \\
\hline Spanias et al. 2015 [39] & Multiple & 8 & 300 & $\begin{array}{l}\text { EMG } \\
\text { Mech }\end{array}$ & $\begin{array}{c}\text { MAV, SSC, } \\
\text { WL, ZC, AR } \\
\text { Mean, Max, } \\
\text { Min, SD, IV, } \\
\text { FV }\end{array}$ & DBN & $\sim 99$ \\
\hline Spanias et al. 2016a [40] & Multiple & 2 & 300 & $\begin{array}{l}\text { EMG } \\
\text { Mech }\end{array}$ & $\begin{array}{c}\text { MAV, SSC, } \\
\text { WL, ZC, AR } \\
\text { Mean, Max, } \\
\text { Min, SD }\end{array}$ & DBN & NR \\
\hline Spanias et al. 2016b [8] & Multiple & 8 & 300 & Mech & $\begin{array}{c}\text { Mean, Max, } \\
\text { Min, SD, IV, } \\
\text { FV }\end{array}$ & DBN & 96.7 \\
\hline Spanias et al. 2017 [41] & Multiple & 8 & 300 & Mech & $\begin{array}{l}\text { Mean, Max, } \\
\text { Min, SD, IV, } \\
\text { FV }\end{array}$ & DBN & 98.8 \\
\hline Spanias et al. 2018 [42] & Multiple & 4 & 300 & $\begin{array}{l}\text { EMG } \\
\text { Mech }\end{array}$ & $\begin{array}{c}\text { MAV, SSC, } \\
\text { WL, ZC, AR } \\
\text { Mean, Max, } \\
\text { Min, SD, IV, } \\
\text { FV }\end{array}$ & DBN & 95.97 \\
\hline Stolyarov et al. 2017 [43] & Unique & 1 & FF to $\mathrm{FO}$ & Mech & $\begin{array}{l}\text { Mean, Max, } \\
\text { Min, SD }\end{array}$ & LDA & 94.1 \\
\hline Su et al. 2019 [44] & Unique & 1 & 490 & Mech & Raw Data & $\mathrm{CNN}$ & 89.2 \\
\hline Tkach et al. 2013 [45] & Multiple & 3 & 250 & $\begin{array}{l}\text { EMG } \\
\text { Mech }\end{array}$ & $\begin{array}{c}\text { MAV, SSC, } \\
\text { WL, ZC } \\
\text { Mean, SD }\end{array}$ & LDA & 96 \\
\hline Wang et al. 2013 [46] & Multiple & 4 & 200 & Mech & $\begin{array}{c}\text { Range, AR, } \\
\text { CORR }\end{array}$ & LDA & 99.01 \\
\hline Wang et al. 2018 [47] & Sliding & NA & 50 pts & Mech & Raw Data & LSTM & 95 \\
\hline
\end{tabular}


Table 3. Cont.

\begin{tabular}{|c|c|c|c|c|c|c|c|}
\hline \multirow{2}{*}{ Article } & \multicolumn{3}{|c|}{ Analysis Windows } & \multirow{2}{*}{ Sensors } & \multirow{2}{*}{ Features } & \multirow{2}{*}{ Algorithm } & \multirow{2}{*}{ Accuracy } \\
\hline & Type & Number & Length & & & & \\
\hline Woodward et al. 2016 [48] & Multiple & 2 & 300 & Mech & $\begin{array}{l}\text { Mean, Max, } \\
\text { Min, SD, IV, } \\
\text { FV }\end{array}$ & ANN & 98.9 \\
\hline Xu et al. 2018 [49] & Sliding & NA & 250 & Mech & $\begin{array}{l}\text { Mean, Max, } \\
\text { Min, SD, Diff }\end{array}$ & QDA & 93.2 \\
\hline Young et al. 2013a [50] & Multiple & 8 & 300 & $\begin{array}{l}\text { EMG } \\
\text { Mech }\end{array}$ & $\begin{array}{c}\text { MAV, SSC, } \\
\text { WL, ZC, AR } \\
\text { Mean, Max, } \\
\text { Min, SD }\end{array}$ & DBN & 98.2 \\
\hline Young et al. 2013b [51] & Multiple & 8 & 300 & Mech & $\begin{array}{l}\text { Mean, Max, } \\
\text { Min, SD }\end{array}$ & $\mathrm{DBN}$ & $\sim 98$ \\
\hline Young et al. 2013c [52] & Multiple & 2 & 300 & $\begin{array}{l}\text { EMG } \\
\text { Mech }\end{array}$ & $\begin{array}{c}\text { MAV, SSC, } \\
\text { WL, ZC, AR } \\
\text { Mean, Max, } \\
\text { Min, SD }\end{array}$ & LDA & 86.4 \\
\hline Young et al. 2014a [53] & Multiple & 2 & 250 & Mech & $\begin{array}{l}\text { Mean, Max, } \\
\text { Min, SD }\end{array}$ & LDA & $\sim 99$ \\
\hline Young et al. 2014b [54] & Multiple & 8 & 300 & $\begin{array}{l}\text { EMG } \\
\text { Mech }\end{array}$ & $\begin{array}{c}\text { MAV, SSC, } \\
\text { WL, ZC, AR } \\
\text { Mean, Max, } \\
\text { Min, SD }\end{array}$ & DBN & $\sim 99$ \\
\hline Young et al. 2016 [55] & Multiple & 8 & 300 & Mech & $\begin{array}{c}\text { Mean, Max, } \\
\text { Min, SD, IV, } \\
\text { FV }\end{array}$ & DBN & $\sim 99$ \\
\hline Zhang et al. 2011 [56] & Sliding & NA & 150 & $\begin{array}{l}\text { EMG } \\
\text { Mech }\end{array}$ & $\begin{array}{c}\text { MAV, SSC, } \\
\text { WL, ZC } \\
\text { Mean, Max, } \\
\text { Min }\end{array}$ & LDA & $>97$ \\
\hline Zhang et al. 2013 [57] & Sliding & NA & 150 & $\begin{array}{l}\text { EMG } \\
\text { Mech }\end{array}$ & $\begin{array}{c}\text { MAV, SSC, } \\
\text { WL, ZC } \\
\text { Mean, Max, } \\
\text { Min }\end{array}$ & SVM & 95 \\
\hline Zhang et al. 2019 [58] & Sliding & NA & 600 & $\begin{array}{c}\text { Depth } \\
\text { Camera }\end{array}$ & Raw data & $\begin{array}{l}\mathrm{CNN}+ \\
\mathrm{HMM}\end{array}$ & 96.4 \\
\hline Zhang et al. 2019 [59] & Sliding & NA & 733 & $\begin{array}{l}\text { Depth } \\
\text { Camera }\end{array}$ & Raw data & $\mathrm{CNN}$ & 94.9 \\
\hline Zhang et al. 2012 [60] & Sliding & NA & 160 & $\begin{array}{l}\text { EMG } \\
\text { Mech }\end{array}$ & $\begin{array}{c}\text { MAV, SSC, } \\
\text { WL, ZC } \\
\text { Mean, Max, } \\
\text { Min }\end{array}$ & LDA & 97.6 \\
\hline Zheng et al. 2013 [61] & Sliding & NA & 250 & Capacitive & $\begin{array}{l}\text { Mean, Max, } \\
\text { Min, SD, } \\
\text { sum }(\operatorname{abs}(\operatorname{diff}(X))) \text {, } \\
\text { mean }(\operatorname{diff}(X)) \text {, } \\
\text { sum }(\operatorname{abs}(X)) \\
\text { Std(abs(diff(X))), } \\
\text { CORR }\end{array}$ & QDA & 95 \\
\hline Zheng et al. 2014 [62] & Sliding & NA & 250 & Capacitive & $\begin{array}{c}\text { Mean, Max, } \\
\text { Min, SD, } \\
\text { sum }(\operatorname{abs}(\operatorname{diff}(X))) \text {, } \\
\text { mean }(\operatorname{diff}(X)) \text {, } \\
\text { sum }(\operatorname{abs}(X)) \\
\text { Std }(\operatorname{abs}(\operatorname{diff}(X))) \text {, } \\
\text { CORR }\end{array}$ & QDA & 95.1 \\
\hline
\end{tabular}


Table 3. Cont.

\begin{tabular}{|c|c|c|c|c|c|c|c|}
\hline \multirow{2}{*}{ Article } & \multicolumn{3}{|c|}{ Analysis Windows } & \multirow{2}{*}{ Sensors } & \multirow{2}{*}{ Features } & \multirow{2}{*}{ Algorithm } & \multirow{2}{*}{ Accuracy } \\
\hline & Type & Number & Length & & & & \\
\hline Zheng et al. 2016 [63] & Sliding & NA & 250 & $\begin{array}{c}\text { Capacitive } \\
\text { Mech }\end{array}$ & $\begin{array}{l}\text { Mean, Max, } \\
\text { Min, SD, } \\
\text { sum }(\operatorname{abs}(\operatorname{diff}(X))) \text {, } \\
\text { sum }(\operatorname{abs}(X)) \\
\text { Mean, Max, } \\
\text { Min, SD }\end{array}$ & SVM & 95.8 \\
\hline Zheng et al. 2019 [64] & Sliding & NA & 250 & Mech & $\begin{array}{l}\text { Mean, Max, } \\
\text { SD }\end{array}$ & SVM & 92.7 \\
\hline Zhou et al. 2019 [65] & Sliding & NA & 150 & Mech & $\begin{array}{c}\text { Mean, Max, } \\
\text { Min, SD, RMS }\end{array}$ & SVM & $>90$ \\
\hline
\end{tabular}

Analysis Windows: Type: Three types of analysis windows are used: sliding windows, multiple windows, unique window. Number: When using multiple windows, the number of windows is reported. NA $=$ Not Applicable (for unique and sliding windows). NP = Not Provided. Length: The window length is reported in $\mathrm{ms}$. When the window length is variable, both the beginning and the end of the window(s) are reported: Gait Cycle = the data of the complete gait cycle are extracted, Stance $=$ The data of the stance phase of the tested side are extracted, FF to FO = the data from Foot Flat to Foot Off (of the tested side) are extracted, FC contro to FC ipsi = the data from the Foot Contact of the contralateral side to the Foot Contact of the ipsilateral side are extracted. If the acquisition frequency was not reported, the window length is reported in terms of point numbers. NP = Not Provided. Sensors: EMG = ElectroMyoGraphs, FMG = ForceMyoGraph, Mech = Mechanical sensors (e.g., IMU, joint angle, joint rotational speed, data from load cell, etc.), for more details refer to Table 3. Features: NP $=$ Not Provided, WT $=$ Wavelet Transform, DTW $=$ Dynamic Time Wrapping, Max $=$ Maximum value, Min = Minimum Value, IV = Initial Value, FV = Final Value, RMS = Root Mean Square, SD = Standard Deviation, $\mathrm{WL}=$ Waveform Length, $\mathrm{ZC}=$ Zero Crossings, SSC = Slope Sign Change, MAD = Mean Absolute Deviation, Diff = Differential Values, $\mathrm{AR}=$ autocorrelation coefficients of an autoregressive model (the number of coefficients and the order of the model are not reported), CORR = Correlation between signals, ICC $=$ Intraclass Correlation Coefficients. Algorithm: (by order of appearance) SVM = Support Vector Machine, HMM = Hidden Markov Model, LDA = Linear Discriminant Analysis, LR = Logistic Regression, EBA = Entropy Based Algorithm, $\mathrm{CNN}=$ Convolutional Neural Network, ANN = Artificial Neural Network, DT = Decision Tree, LIFT = Learning From Testing Data, KNN = K-Nearest Neighbor, DBN = Dynamic Bayesian Network, LSTM = Long-Short Term Memory network, QDA = Quadratic Discriminant Analysis. Accuracy: NP = Not Provided, NR = Not Reported (in Huang et al. [23] and in Spanias et al. [40], the influence of simulated noise on the EMG was tested, the reported accuracies were lower and were not comparable to other studies), A ' ' sign means that results were obtained from reading graphs un the paper.

\subsubsection{Features}

The detailed features and domains used in each study can be found in Table 3 .

Two main domains of features have been investigated in the included studies: time-domain (e.g., mean, minimum, maximum, standard deviation, etc.) $(\mathrm{N}=48)$ and time-frequential domain features (e.g., coefficients of the wavelet transform) $(\mathrm{N}=1)$. One study compared the performances of machine learning algorithm using either time-domain features or time-frequency domain features [9].

The remaining studies did not provide any information concerning the features used $(\mathrm{N}=1)$ or used the temporal data measured by the sensors and did not extract any features $(\mathrm{N}=7)$.

\subsubsection{Machine Learning Algorithms and Their Accuracies}

Details on the machine learning algorithms used in studies and their reported accuracies are presented in Table 3.

Most of the studies used the classical pattern recognition algorithms (Bishop 2006 [66]) which are available. Three algorithms were implemented more often than others: Linear Discriminant Analysis (LDA) $(\mathrm{N}=29)$, Support Vector Machines (SVM) $(\mathrm{N}=17)$ and Dynamic Bayesian Network $(\mathrm{DBN})(\mathrm{N}=10)$. Other algorithms were investigated a few times. Quadratic Discriminant Analysis (QDA) $(\mathrm{N}=8)$ was used either with data from Capacitive Sensing Systems $(\mathrm{N}=4)$ or from Inertial Motion Units $(\mathrm{N}=4)$. Small Artificial Neural Networks (ANN) with 1 or 2 hidden layers were used to recognize the current locomotion mode $(\mathrm{N}=6)$ or to predict the upcoming locomotion mode $(\mathrm{N}=1)$. Convolutional Neural Networks $(\mathrm{CNN})(\mathrm{N}=4)$ have started to be applied more recently for locomotion mode classification (since 2019). CNNs were essentially used to avoid feature selection: all studies 
using CNNs did not extract any feature and instead fed raw sensor data into the algorithm. Other algorithms were used only once (K-Nearest Neighbors-KNN and Long Short-Term Memory neural networks - LSTM) or twice (Decision Tree-DT and Hidden Markov Model-HMM).

Some less typical adaptive algorithms were also sometimes used. Learning From Testing data (LIFT) and Entropy Based Algorithm (EBA) were each used twice and Transductive SVM was used once $[15,27]$.

\section{Discussion}

This systematic review included 58 articles implementing Machine Learning classifiers designed to identify the locomotion mode of assistive device user. Such algorithms were generally implemented as high-level controllers able to automatically adapt the behavior of lower limb prostheses, exoskeletons, or orthoses. We used the PubMed and Web of Science core collection databases for finding our references. This was done because most medical related literature (including biomedical engineering) can be found in these two databases. In addition, we performed an extensive search through the references of the papers from the aforementioned databases. As we were focusing on medical literature, we did not include Scopus as one of the databases for this review. This may have led to a very small number of papers that have not been included in this review.

Accuracy and the robustness (e.g., stable performance in the face of long-term use) of the algorithm were the variables most often used to report the results from studies investigating locomotion on different terrains. The influence of (1) sensors, (2) analysis windows and features, (3) machine learning algorithms on the accuracy and on the robustness of the locomotion mode classifiers are discussed below. It should be noted that the accuracies reported in this review are those which were supplied in each paper. Since each study was conducted with different circumstances such as number of subjects and conditions tested, accuracies can be compared within each study but cannot be compared between studies with precision.

\subsection{Influence of Sensor Choice}

Several sensors have been used to build locomotion mode classifiers. The choices of these sensors may influence the accuracy and the robustness of the classifiers. More details are provided in the sections below.

\subsubsection{Algorithm Accuracy}

Among the included studies the three most used sensors were Inertial Motion Units (IMU) ( $N=36$, see Table 2), load cells ( $\mathrm{N}=31$, Table 2$)$ and electromyographs (EMG) $(\mathrm{N}=21$, Table 2).

Firstly, IMUs measure the acceleration and the rotational speed along three orthogonal axes. For example, Stolyarov et al. [43] classified level-ground walking (LW), stair ascent (SA), stair descent (SD), ramp ascent (RA) and ramp descent (RD) with LDA. They showed that including trajectory information of the prosthesis increased the averaged accuracy compared to using only the accelerations and rotational speeds (from $80.9 \%$ to $94.1 \%$ ). They suggested using filtering techniques to reduce drift (e.g., Kalman filters, particle filters, etc.). These researchers also brought up the point that the performance of the classification algorithms might be reduced when applied to gait at slow walking speed. Other researchers demonstrating the capacity of IMUs for the detection of locomotion mode were Zhou et al. [65]. They were able with the SVM to classify three locomotion modes (LW, SA, SD) with the exclusive use of IMU data. They achieved above $90 \%$ accuracy using orientation information. The signals combining acceleration, rotational speed and orientation were directly extracted from the IMUs (MPU 9250, Ivensense ${ }^{\circledR}$ — the filter technique was not reported in the data sheet of the sensor).

However, these studies suggested that the algorithm performances could increase when fusing IMUs signals with other sensors signals. Thus, in most studies using IMUs, information from this sensor was fused with measurements from other sensors (see below). 
Secondly, load cells measured the interaction force between the device and the user. For example, Huang et al. [24] classified five locomotion modes (LW, SA, SD, RA, RD) with LDA and SVM by using only a 6 degrees of freedom (DOF) load cell mounted on the prosthetic pylon of an above-knee prosthesis. The phase-dependent strategy achieved 85 to $95 \%$ accuracy during stance phase (Initial Double Limb Stance (DS1), Single Limb Stance (SS) and Terminal Double Limb Stance (DS2)) but the accuracies dropped to 50-60\% during swing (SW) phase for both LDA and SVM classifiers. Similar drops in accuracy were reported when using only plantar pressure measurements [13,46]. According to the authors [24], the low classification accuracies in the swing phase were almost certainly due to low forces/moments generated during swing phase.

Thirdly, EMG signals measured from the residual limb were reported to contain useful information for locomotion mode predictions in early studies. Indeed, for example, Huang et al. [24] and Miller et al. [33] achieved classification of five locomotion modes (LW, SA, SD, RA, RD) using EMG signals measured in the residual limb of patients with transfemoral and transtibial unilateral amputation respectively. LDA and SVM classifiers were used in both studies. For volunteers with transfemoral amputation [24], the SVM achieved an accuracy of above $90 \%$ for all phases. The LDA algorithm achieved similar accuracies in the stance phase but a slightly lower accuracy of $85 \%$ in the swing phase. For volunteers with transtibial amputation [33], both LDA and SVM algorithms achieved around 98\% accuracy. Many researchers have pointed out that the EMG signals suffer from disturbances especially because of shifts in electrode position when donning and doffing a prosthesis for example. Miller et al. [33] reported a mean loss in accuracy of $15.8 \%$ and $23.1 \%$ for LDA and SVM classifiers when the medial gastrocnemius electrode was shifted. Both studies concluded that EMG signals could be helpful for classifying locomotion modes as long as the signals are not disturbed. Several studies have provided suggestions for reducing these problems. They are discussed in the 'Algorithm robustness' Section 4.1.2 below.

Finally, sensor fusion has been proven to significantly increase accuracies of locomotion mode classifiers [24,54]. For example, Huang et al. [24] observed an increase in accuracy by combining EMG and load cell data instead of using either only EMG data or only load cell data (accuracy increase of up to $5.9 \%$ for an SVM classifier). Since then, data from different sensors have been fused together to reach higher accuracies. In another example, Young et al. [54] used 13 mechanical sensors (IMU, load cell, position, velocity and torque at knee and ankle joints) and recorded EMG signals from 9 muscles of the residual limb of volunteers with a transfemoral amputation. A DBN algorithm predicting upcoming locomotion modes reached $99 \%$ accuracy for steady-state steps and $88 \%$ accuracy for transitional steps.

\subsubsection{Algorithm Robustness}

Sensors measurement noise over time can affect the performances of locomotion mode classifiers. To achieve reliable behavior of locomotion assistive device for long-term use, the influence of such noise should be considered. Techniques implemented to take into account sensors noise are discussed here.

EMG signals were mostly reported to be disturbed by environmental noise, electrode conductivity changes, shifts in electrode position or even loss of electrode contact $[67,68]$. Three techniques have been used to cope with such disturbances. The first one aims at training ML algorithm with several electrode displacement configurations [33]. The second one consists of building a sensor fault detection system so that disturbed EMG channel are removed if detected as noisy $[23,40]$. The third one uses an adaptive framework so that ML algorithm can be updated when EMG signals are disturbed [42]. The latter adaptive algorithm also included a sensor fault detection system. Alternatively, according to some researchers [62,63], capacitive sensing systems, measuring the gap change between the residual limb and the prosthetic socket [63], could eventually replace EMG signals since such sensors appear to be robust to donning and doffing an ankle-knee prosthesis and to load bearing changes [62]. 


\subsection{Influence of Analysis Windows}

In this section, we will discuss the influence of the analysis window configuration on the accuracy of locomotion mode prediction.

Among the included studies, sliding $(\mathrm{N}=30$, Table 3$)$ and multiple $(\mathrm{N}=19$, Table 3$)$ analysis windows were the preferred configurations. While the implementation of sliding windows requires the building of one classifier per gait phase, the implementation of multiple windows is performed by building one classifier per analysis window [50-55]. The number of classifiers depends on the number of gait phases for sliding windows and depends on the number of windows for multiple windows. In the case of sliding windows, Chen et al. [12] observed that the number of phases for phase-dependent classification significantly influences algorithm accuracy. As a result, using four gait phases (DS1, SS, DS2, SW) increased the accuracy of both LDA and QDA compared to when using only two phases (Stance, Swing). As the sliding window method generally involves a longer portion of the gait phase in question, the data to be classified are generally more variable.

Several studies reported that the length of analysis windows had a significant impact on algorithm performances for multiple window [53,54] and sliding window [22] configurations. Young et al. [53,54], using multiple windows, showed that there was an optimal window length (between 200 and 300 ms) for classification accuracies using mechanical and EMG data for both steady state and transitional data. The same was found in a study using sliding windows, where the length of the window but not its increments were found to affect algorithm performances [22]. For online implementation however smaller window increment ensures a faster response time since locomotion mode classification is performed more often.

More recently, some researchers did not use analysis windows which ended at classic gait events like foot contact but instead allowed for a delay in the termination of the analysis window. For example, Simon et al. [37,69] had an analysis window which ended 90ms after foot contact or foot off. This delay increased the accuracy of a DBN algorithm and did not affect the stability of the users of a powered above-knee prosthesis.

\subsection{Influence of Features}

The features set used in each study was highly dependent on the sensors used.

For EMG signals, two types of features were tested: (1) time-domain features and (2) time-frequential domain features. The most commonly used time-domain features were mean absolute value, waveform length, number of zero crossings, number of slope sign changes $(\mathrm{N}=21)$ and the coefficients of autoregressive models $(\mathrm{N}=8)$. For time-frequential domain features, the coefficients of the wavelet transform of EMG signals were used once [9]. Ai et al. [9] compared LDA and SVM performances when using time-domain features or time-frequency domain features. Both algorithms reached higher accuracies with time domain features for one volunteer with below-knee amputation, e.g., in the case of the SVM 91.9\% with time-domain features vs. $82.3 \%$ with time-frequency features. Additionally, time-domain features were easier and faster to compute [9].

A large number of studies ( $\mathrm{N}=48$, Table 3 ) used mechanical sensors (IMU, load cells, encoders, pressure insoles, etc.). The most representative feature $(\mathrm{N}=34$, Table 3$)$ set was a combination of the following time-domain features: mean, maximum, minimum and standard deviation. Initial and final values were also sometimes added to the feature set $(\mathrm{N}=8$, Table 3$)$.

Finally, several feature reduction techniques were sometimes used to find the minimal feature set necessary for successful classification and to avoid overfitting $(\mathrm{N}=14)$ : Wrapper techniques such as Sequential Forward Selection (SFS) and Selection Backward Selection (SBS) were used to pick the features having the highest impact on the classification accuracy [39] $(\mathrm{N}=8)$. Such methods are time consuming [18]. Zhang et al. [57] compared the processing time taken by two wrapper methods and a filter method. The filter method was found to be faster compared to wrapper methods (84 s for the filter method vs. $1978 \mathrm{~s}$ for SBS). 


\subsection{Influence of Machine Learning Algorithm}

\subsubsection{On Accuracy}

A variety of ML algorithms were used in the included studies. The most frequently used algorithms were LDA ( $\mathrm{N}=29$, Table 3), SVM ( $=19$, Table 3$)$ and DBN ( $=10$, Table 3). Also, CNNs were used to avoid features selection $(\mathrm{N}=4$, Table 3$)$.

LDA is easy to implement since no hyperparameters need to be tuned $[48,70]$. This algorithm is fast (1.29 ms [48], $0.078 \mathrm{~ms}$ with parallelization [32]) and not prone to overfitting [9]. For these reasons, this algorithm is often used as a baseline for performance comparisons between several algorithms [32,42]. More importantly, in some studies, LDA obtained accuracies similar to neural networks [48] and to SVM [33].

Even though, hyperparameters such as kernel parameter and the penalty factor need to be tuned for SVM [16], optimization techniques (e.g., grid search [9], particle swarm optimization [29]) have been found in some studies to reach slightly better performances than LDA [9,24] or QDA [62].

One of the first researchers to use DBNs were Young et al. in 2013 [50,51]. By adding past information to those of the current state, the DBN was able to obtain higher classification accuracies than LDA [54] (88\% vs. 85\% for transitional accuracies for DBN and LDA respectively). The DBN, unlike LDA with uniform priors, take transitional probabilities into account (e.g., in stair ascent mode, the next mode is more likely to be stair ascent or level ground walking).

Finally, CNNs were recently used in a few studies [16,44,58,59]. For example, Zhang et al. [58,59] used depth-images with a depth-camera coupled with an IMU mounted on the prosthetic pylon of an above-knee prosthesis. CNNs, known to perform well when handling image datasets are often used to avoid manual feature selection. CNNs were also used in the case of non-image data, e.g., IMU data [44] or load cell data [16]. All four studies using CNNs reported an accuracy above $89 \%$ but none of those studies implemented the designed CNN online.

The most common mistake was misclassification between ramp ascent and level ground walking modes [50]. Grouping ramp ascent and level walking classes were reported to improve the performances of locomotion mode classifiers [50]. Such a technique is relevant when the control laws (impedance in $[43,50])$ are similar for both modes. Zhang et al. [59] evaluated the influence of such errors (misclassifications between level walking and incline walking) on the stability of the user of an above-knee prosthesis using angular momentum and a subjective questionnaire. It was observed that the effect of the errors depends on the type of error, the error duration, and the gait phase where the error occurred. Errors were considered critical if the stability of prosthesis users was disturbed. This appears to be a good criterion for evaluating the importance of errors when designing a locomotion mode classifier.

\subsubsection{On Robustness}

Very few studies have evaluated the performances of locomotion mode classifiers for long term use. Adaptive frameworks have been proposed to deal with EMG disturbances [42] or to achieve stable performances for long term use [27]. For example, Spanias et al. [42], designed a forward predictor and a backward estimator. The forward predictor is an ML algorithm designed to predict the upcoming locomotion mode of an assistive device user. The backward estimator is an ML algorithm designed to recognize the current locomotion mode. The latter algorithm was used to label new data. Then, the newly labelled data were incorporated into the training set and then used to update the forward predictor parameters. Spanias et al. [42] used this framework to deal with EMG disturbances. The adaptive algorithm learned to reincorporate disturbed EMG channels over time. The adaptive algorithm was reported to perform significantly better than a non-adaptive algorithm. In another example, Liu et al. [27] evaluated the performance of adaptive algorithms compared to a non-adaptive algorithm across multiple session within a single experimental day. After donning and doffing the prosthesis, the adaptive algorithms were reported to update classifiers boundaries and to 
recover initial accuracy whereas the performances of the non-adaptive algorithms gradually decreased. To sum up, adaptive frameworks seem to be a promising solution to achieve long-term locomotion mode classification.

\subsection{Propositions for Future Work}

This systematic review included 58 articles published between 1 January 2000 and 31 July 2020. All 58 articles implemented ML-based locomotion mode classifiers designed for users of lower limb assistive devices. As can be seen from Table 3, classification accuracies under the tested conditions were almost always very high, hence indicating good progress in the attempts to construct more intelligent prosthetic devices. Nevertheless, there is always room for improvement. We try here to propose some recommendations concerning the research reports in the field as well as suggestions for moving forward with the implementation of these devices in the daily lives of the patients.

\subsubsection{Homogenization of Reports}

We will start first with the question of terms that are used in the field. This is not a trivial matter as the homogenization of terms would increase the understanding between researchers and hence speed up progress. There is much confusion around the use of terms recognition and prediction. The two terms are used in an interchangeable manner across studies but do not refer to the same goal. We propose that classifying the locomotion mode before the critical timing can be considered as a prediction task while a classification made after the critical timing can be considered as a recognition task. For recall, the critical timing is the latest moment when the behavior of the locomotion assistive device can be adapted to the new locomotion mode without disturbing the user. A more discriminating use of the two terms, recognition and prediction, would ease the comprehension of the studies.

The report of accuracies also suffers from a similar lack of precision. While many reports have distinguished between accuracies during steady state and the transitional step, several have not. Adding together the success obtained in steady state with that which is obtained in transitional steps is misleading, as the errors made in the latter tend to be higher. We therefore propose that there should be a systematic distinction of accuracies for these two modes.

\subsubsection{Recommendations for Generalization to Daily Life Conditions}

The review shows that significant progress has been made in the efforts to ease the use of prosthetic devices across multiple terrains. Nevertheless, some obvious steps are necessary to move ahead with ensuring the comfortable use of these devices in the daily lives of the patients.

An obvious thing to add on the list would be the inclusion of more daily life conditions for testing the devices. Examples of these would be different angles of approaches towards stairs or slope $[9,28]$, different staircases [18] or load bearing changes [51]. A good extension for many of the studies included in this review would be a test of the algorithms outside the laboratory. Only a very small number of studies managed to take this step. For example, the work of Zhang et al. [58,59] evaluated a CNN classifier with data acquired both indoors and outdoors. Such studies are to be encouraged.

Another important condition to be included, to make the prosthetic devices more usable in daily life, would be the integration of multiple speeds in the study. Once again, very few researchers have investigated this condition. One researcher who has taken a step in this direction is Liu et al., 2017 [28].

A third variation which is not often taken into consideration is the transitioning leg which is used when entering a new terrain. While subjects tend to use one leg more than the other when crossing into new conditions, the side used is not always identical and subjects can change the transitioning leg. A handful of studies such as one by Zhou et al. [65] have taken this into account. They reported better accuracies when the locomotion mode classifier was trained with data from both transitioning legs. This may be a simple condition to include in more of the future studies in the field.

We turn here, from a discussion of conditions to be tested, to comments on how to decrease the burden of developing an algorithm which is tuned to each patient. The process of gathering data 
for the purpose of training the ML algorithm for each patient can be long and burdensome. A few researchers have provided recommendations on how to reduce the difficulty of this step. For example, Zhang et al. [60] proposed an automatic training method through environmental sensing. A radar distance meter coupled with an IMU helped to sense the environment and to automatically label the acquired data. Automatic labelling could also be achieved with depth cameras [58,59]. Another step in this direction has been the use of subject independent models which could potentially reduce the amount of training data needed. Efforts of this type have been made by Young et al. [52] and Spanias [8]. It seems that the addition of this step to future investigations of predictive or recognition algorithms would provide the additional bonus of reduced training time for the patient.

Supplementary Materials: The following are available online at http://www.mdpi.com/1424-8220/20/21/6345/s1, S1: Detailed Search Strategy, S2: Quality Assessment of the studies, Table S2: Detailed quality scores of the included studies, Table S3: EMG used in the studies, S4: References of the supplementary material.

Author Contributions: Conceptualization, D.L. and E.T.; methodology, D.L., F.L., M.G.; validation, D.L., E.T., F.L. and P.O.; investigation, D.L., F.L., L.C.; resources, F.L. and L.C.; data curation, F.L., V.O.; writing-original draft preparation, F.L.; writing-review and editing, D.L., E.T., L.C., V.O., P.O., M.G.; visualization, F.L.; supervision, F.L. and E.T.; project administration, D.L.; funding acquisition, D.L., E.T. and L.C. All authors have read and agreed to the published version of the manuscript. Authorship must be limited to those who have contributed substantially to the work reported.

Funding: This research was funded by Conseil Régional de Bourgogne Franche Comté and supported by university Hospital of Dijon. F.L. is supported by a PhD grant from Conseil Régional de Bourgogne Franche Comté.

Acknowledgments: Authors want to thank all staff of the university of Burgundy and University Hospital of Dijon for their help for funding and during the manuscript preparation. Authors want to thank Lucile Antonini for her help for the Figure 2.

Conflicts of Interest: The authors declare no conflict of interest.

\section{References}

1. Goujon-Pillet, H.; Drevelle, X.; Bonnet, X.; Villa, C.; Martinet, N.; Sauret, C.; Bascou, J.; Loiret, I.; Djian, F.; Rapin, N.; et al. APSIC: Training and fitting amputees during situations of daily living. IRBM 2014, 35, 60-65. [CrossRef]

2. Johansson, J.L.; Sherrill, D.M.; Riley, P.O.; Bonato, P.; Herr, H. A Clinical Comparison of Variable-Damping and Mechanically Passive Prosthetic Knee Devices. Am. J. Phys. Med. Rehabil. 2005, 84, 563-575. [CrossRef]

3. Au, S.K.; Weber, J.A.; Herr, H.M. Powered Ankle-Foot Prosthesis Improves Walking Metabolic Economy. IEEE Trans. Robot. 2009, 25, 51-66. [CrossRef]

4. Tucker, M.R.; Olivier, L.; Pagel, A.; Bleuler, H.; Bouri, M.; Lambercy, O.; Millán, J.D.R.; Riener, R.; Vallery, H.; Gassert, R. Control strategies for active lower extremity prosthetics and orthotics: A review. J. Neuroeng. Rehabil. 2015, 12, 1. [CrossRef]

5. Sup, F.; Varol, H.A.; Mitchell, J.; Withrow, T.J.; Goldfarb, M. Preliminary Evaluations of a Self-Contained Anthropomorphic Transfemoral Prosthesis. IEEE/ASME Trans. Mechatron. 2009, 14, 667-676. [CrossRef] [PubMed]

6. Moher, D.; Liberati, A.; Tetzlaff, J.; Altman, D.G. Preferred Reporting Items for Systematic Reviews and Meta-Analyses: The PRISMA Statement. PLoS Med. 2009, 6, 7. [CrossRef] [PubMed]

7. Kmet, L.M.; Lee, R.C.; Cook, L.S.; Alberta Heritage Foundation for Medical Research. Standard Quality Assessment Criteria for Evaluating Primary Research Papers from a Variety of Fields; Alberta Heritage Foundation for Medical Research: Edmonton, AB, Canada, 2004.

8. Spanias, J.; Simon, A.M.; Perreault, E.J.; Hargrove, L.J. Preliminary results for an adaptive pattern recognition system for novel users using a powered lower limb prosthesis. In Proceedings of the 2016 38th Annual International Conference of the IEEE Engineering in Medicine and Biology Society (EMBC), Orlando, FL, USA, 17-20 August 2016; Volume 2016, pp. 5083-5086.

9. Ai, Q.; Zhang, Y.; Qi, W.; Liu, Q.; Chen, K. Research on Lower Limb Motion Recognition Based on Fusion of sEMG and Accelerometer Signals. Symmetry 2017, 9, 147. [CrossRef] 
10. Beil, J.; Ehrenberger, I.; Scherer, C.; Mandery, C.; Asfour, T. Human Motion Classification Based on Multi-Modal Sensor Data for Lower Limb Exoskeletons. In Proceedings of the 2018 IEEE/RSJ International Conference on Intelligent Robots and Systems (IROS), Madrid, Spain, 1-5 October 2018; pp. 5431-5436.

11. Chen, B.; Zheng, E.; Fan, X.; Liang, T.; Wang, Q.; Wei, K.; Wang, L. Locomotion Mode Classification Using a Wearable Capacitive Sensing System. IEEE Trans. Neural Syst. Rehabil. Eng. 2013, 21, 744-755. [CrossRef] [PubMed]

12. Chen, B.; Zheng, E.; Wang, Q.; Wang, L. A new strategy for parameter optimization to improve phase-dependent locomotion mode recognition. Neurocomputing 2015, 149, 585-593. [CrossRef]

13. Chen, B.; Wang, X.; Huang, Y.; Wei, K.; Wang, Q. A foot-wearable interface for locomotion mode recognition based on discrete contact force distribution. Mechatronics 2015, 32, 12-21. [CrossRef]

14. Du, L.; Zhang, F.; Liu, M.; Huang, H. Toward Design of an Environment-Aware Adaptive LocomotionMode-Recognition System. IEEE Trans. Biomed. Eng. 2012, 59, 2716-2725. [CrossRef]

15. Du, L.; Zhang, F.; He, H.; Huang, H. Improving the performance of a neural-machine interface for prosthetic legs using adaptive pattern classifiers. In Proceedings of the 2013 35th Annual International Conference of the IEEE Engineering in Medicine and Biology Society (EMBC), Osaka, Japan, 3-7 July 2013; Volume 2013, pp. 1571-1574.

16. Feng, Y.; Chen, W.; Wang, Q. A strain gauge based locomotion mode recognition method using convolutional neural network. Adv. Robot. 2019, 33, 254-263. [CrossRef]

17. Godiyal, A.K.; Mondal, M.; Joshi, S.D.; Joshi, D. Force Myography Based Novel Strategy for Locomotion Classification. IEEE Trans. Human-Mach. Syst. 2018, 48, 648-657. [CrossRef]

18. Gong, C.; Xu, D.; Zhou, Z.; Vitiello, N.; Wang, Q. Real-Time on-Board Recognition of Locomotion Modes for an Active Pelvis Orthosis. In Proceedings of the 2018 IEEE-RAS 18th International Conference on Humanoid Robots (Humanoids), Beijing, China, 6-9 November 2018; pp. 346-350.

19. Gong, C.; Xu, D.; Zhou, Z.; Vitiello, N.; Wang, Q. BPNN-Based Real-Time Recognition of Locomotion Modes for an Active Pelvis Orthosis with Different Assistive Strategies. Int. J. Hum. Robot. 2020, 17, 2050004. [CrossRef]

20. Hernandez, R.; Zhang, F.; Zhang, X.; Huang, H.; Yang, Q. Promise of a low power mobile CPU based embedded system in artificial leg control. In Proceedings of the 2012 Annual International Conference of the IEEE Engineering in Medicine and Biology Society, San Diego, CA, USA, 28 August-1 September 2012; Volume 2012, pp. 5250-5253.

21. Hernandez, R.; Yang, Q.; Huang, H.; Zhang, F.; Zhang, X. Design and implementation of a low power mobile CPU based embedded system for artificial leg control. In Proceedings of the 2013 35th Annual International Conference of the IEEE Engineering in Medicine and Biology Society (EMBC), Osaka, Japan, 3-7 July 2013; Volume 2013, pp. 5769-5772.

22. Huang, H.; Kuiken, T.A.; Lipschutz, R.D. A Strategy for Identifying Locomotion Modes Using Surface Electromyography. IEEE Trans. Biomed. Eng. 2009, 56, 65-73. [CrossRef]

23. Huang, H.; Zhang, F.; Sun, Y.L.; He, H. Design of a robust EMG sensing interface for pattern classification. J. Neural Eng. 2010, 7, 056005. [CrossRef] [PubMed]

24. Huang, H.; Zhang, F.; Hargrove, L.J.; Dou, Z.; Rogers, D.R.; Englehart, K.B. Continuous Locomotion-Mode Identification for Prosthetic Legs Based on Neuromuscular-Mechanical Fusion. IEEE Trans. Biomed. Eng. 2011, 58, 2867-2875. [CrossRef]

25. Kim, H.; Shin, Y.J.; Kim, J. Kinematic-based locomotion mode recognition for power augmentation exoskeleton. Int. J. Adv. Robot. Syst. 2017, 14, 172988141773032. [CrossRef]

26. Liu, M.; Wang, D.; Huang, H.H. Development of an Environment-Aware Locomotion Mode Recognition System for Powered Lower Limb Prostheses. IEEE Trans. Neural Syst. Rehabil. Eng. 2015, 24, 434-443. [CrossRef]

27. Liu, M.; Zhang, F.; Huang, H. (Helen) an Adaptive Classification Strategy for Reliable Locomotion Mode Recognition. Sensors 2017, 17, 2020. [CrossRef]

28. Liu, Z.; Lin, W.; Geng, Y.; Yang, P. Intent pattern recognition of lower-limb motion based on mechanical sensors. IEEE/CAA J. Autom. Sin. 2017, 4, 651-660. [CrossRef]

29. Long, Y.; Du, Z.-J.; Wang, W.-D.; Zhao, G.-Y.; Xu, G.-Q.; He, L.; Mao, X.-W.; Dong, W. PSO-SVM-Based Online Locomotion Mode Identification for Rehabilitation Robotic Exoskeletons. Sensors 2016, 16, 1408. [CrossRef] 
30. Mai, A.; Commuri, S. Gait identification for an intelligent prosthetic foot. In Proceedings of the 2011 IEEE International Conference on Control Applications (CCA), Denver, CO, USA, 28-30 September 2011; pp. 1341-1346.

31. Mai, J.; Xu, D.; Li, H.; Zhang, S.; Tan, J.; Wang, Q. Implementing a SoC-FPGA Based Acceleration System for On-Board SVM Training for Robotic Transtibial Prostheses. In Proceedings of the 2018 IEEE International Conference on Real-time Computing and Robotics (RCAR), Kandima, Maldives, 1-5 August 2018; Institute of Electrical and Electronics Engineers (IEEE): Kandima, Maldives; pp. 150-155.

32. Mai, J.; Chen, W.; Zhang, S.; Xu, D.; Wang, Q. Performance analysis of hardware acceleration for locomotion mode recognition in robotic prosthetic control. In Proceedings of the 2018 IEEE International Conference on Cyborg and Bionic Systems (CBS), Shenzhen, China, 25-27 October 2018; pp. 607-611.

33. Miller, J.D.; Beazer, M.S.; Hahn, M.E. Myoelectric Walking Mode Classification for Transtibial Amputees. IEEE Trans. Biomed. Eng. 2013, 60, 2745-2750. [CrossRef]

34. Moon, D.-H.; Kim, D.; Hong, Y.-D. Development of a Single Leg Knee Exoskeleton and Sensing Knee Center of Rotation Change for Intention Detection. Sensors 2019, 19, 3960. [CrossRef]

35. Pew, C.; Klute, G.K. Turn Intent Detection for Control of a Lower Limb Prosthesis. IEEE Trans. Biomed. Eng. 2017, 65, 789-796. [CrossRef]

36. Shell, C.E.; Klute, G.K.; Neptune, R.R. Identifying classifier input signals to predict a cross-slope during transtibial amputee walking. PLoS ONE 2018, 13, e0192950. [CrossRef]

37. Simon, A.M.; Ingraham, K.A.; Spanias, J.A.; Young, A.J.; Finucane, S.B.; Halsne, E.G.; Hargrove, L.J. Delaying Ambulation Mode Transition Decisions Improves Accuracy of a Flexible Control System for Powered Knee-Ankle Prosthesis. IEEE Trans. Neural Syst. Rehabil. Eng. 2016, 25, 1164-1171. [CrossRef]

38. Spanias, J.A.; Perreault, E.J.; Hargrove, L.J. A strategy for labeling data for the neural adaptation of a powered lower limb prosthesis. In Proceedings of the 2014 36th Annual International Conference of the IEEE Engineering in Medicine and Biology Society, Chicago, IL, USA, 26-30 August 2014; Volume 2014, pp. 3090-3093.

39. Spanias, J.A.; Simon, A.M.; Ingraham, K.A.; Hargrove, L.J. Effect of additional mechanical sensor data on an EMG-based pattern recognition system for a powered leg prosthesis. In Proceedings of the 2015 7th International IEEE/EMBS Conference on Neural Engineering (NER), Montpellier, France, 22-24 April 2015; pp. 639-642.

40. Spanias, J.A.; Perreault, E.J.; Hargrove, L.J. Detection of and Compensation for EMG Disturbances for Powered Lower Limb Prosthesis Control. IEEE Trans. Neural Syst. Rehabil. Eng. 2015, 24, 226-234. [CrossRef]

41. Spanias, J.A.; Simon, A.M.; Hargrove, L.J. Across-user adaptation for a powered lower limb prosthesis. In Proceedings of the 2017 International Conference on Rehabilitation Robotics (ICORR), London, UK, 17-20 July 2017; Volume 2017, pp. 1580-1583.

42. Spanias, J.A.; Simon, A.M.; Finucane, S.B.; Perreault, E.J.; Hargrove, L.J. Online adaptive neural control of a robotic lower limb prosthesis. J. Neural Eng. 2018, 15, 016015. [CrossRef]

43. Stolyarov, R.; Burnett, G.; Herr, H.M. Translational Motion Tracking of Leg Joints for Enhanced Prediction of Walking Tasks. IEEE Trans. Biomed. Eng. 2018, 65, 763-769. [CrossRef]

44. Su, B.; Wang, J.; Liu, S.-Q.; Sheng, M.; Jiang, J.; Xiang, K. A CNN-Based Method for Intent Recognition Using Inertial Measurement Units and Intelligent Lower Limb Prosthesis. IEEE Trans. Neural Syst. Rehabil. Eng. 2019, 27, 1032-1042. [CrossRef] [PubMed]

45. Tkach, D.C.; Hargrove, L.J. Neuromechanical sensor fusion yields highest accuracies in predicting ambulation mode transitions for trans-tibial amputees. In Proceedings of the 2013 35th Annual International Conference of the IEEE Engineering in Medicine and Biology Society (EMBC), Osaka, Japan, 3-7 July 2013; Institute of Electrical and Electronics Engineers (IEEE): Osaka, Japan; Volume 2013, pp. 3074-3077.

46. Wang, X.; Wang, Q.; Zheng, E.; Wei, K.; Wang, L. A Wearable Plantar Pressure Measurement System: Design Specifications and First Experiments with an Amputee. In Intelligent Autonomous Systems 12; Lee, S., Cho, H., Yoon, K.-J., Lee, J., Eds.; Springer: Berlin/Heidelberg, Germany, 2013; Volume 194, pp. 273-281.

47. Wang, C.; Wu, X.; Ma, Y.; Wu, G.; Luo, Y. A Flexible Lower Extremity Exoskeleton Robot with Deep Locomotion Mode Identification. Complexity 2018, 2018, 5712108. [CrossRef] 
48. Woodward, R.B.; Spanias, J.; Hargrove, L. User intent prediction with a scaled conjugate gradient trained artificial neural network for lower limb amputees using a powered prosthesis. In Proceedings of the 2016 38th Annual International Conference of the IEEE Engineering in Medicine and Biology Society (EMBC), Orlando, FL, USA, 17-20 August 2016; Volume 2016, pp. 6405-6408.

49. Xu, D.; Feng, Y.; Mai, J.; Wang, Q. Real-Time On-Board Recognition of Continuous Locomotion Modes for Amputees with Robotic Transtibial Prostheses. IEEE Trans. Neural Syst. Rehabil. Eng. 2018, 26, 2015-2025. [CrossRef]

50. Young, A.J.; Simon, A.; Hargrove, L.J. An intent recognition strategy for transfemoral amputee ambulation across different locomotion modes. In Proceedings of the 2013 35th Annual International Conference of the IEEE Engineering in Medicine and Biology Society (EMBC) Osaka, Japan, 3-7 July 2013; Volume 2013, pp. 1587-1590.

51. Young, A.J.; Simon, A.M.; Fey, N.P.; Hargrove, L.J. Intent Recognition in a Powered Lower Limb Prosthesis Using Time History Information. Ann. Biomed. Eng. 2013, 42, 631-641. [CrossRef] [PubMed]

52. Young, A.J.; Simon, A.M.; Fey, N.P.; Hargrove, L.J. Classifying the intent of novel users during human locomotion using powered lower limb prostheses. In Proceedings of the 2013 6th International IEEE/EMBS Conference on Neural Engineering (NER), San Diego, CA, USA, 6-8 November 2013; pp. 311-314.

53. Young, A.J.; Simon, A.M.; Hargrove, L.J. A Training Method for Locomotion Mode Prediction Using Powered Lower Limb Prostheses. IEEE Trans. Neural Syst. Rehabil. Eng. 2013, 22, 671-677. [CrossRef]

54. Young, A.J.; Kuiken, T.A.; Hargrove, L.J. Analysis of using EMG and mechanical sensors to enhance intent recognition in powered lower limb prostheses. J. Neural Eng. 2014, 11, 056021. [CrossRef]

55. Young, A.J.; Hargrove, L.J. A Classification Method for User-Independent Intent Recognition for Transfemoral Amputees Using Powered Lower Limb Prostheses. IEEE Trans. Neural Syst. Rehabil. Eng. 2015, 24, 217-225. [CrossRef]

56. Zhang, F.; Disanto, W.; Ren, J.; Dou, Z.; Yang, Q.; Huang, H. A Novel CPS System for Evaluating a Neural-Machine Interface for Artificial Legs. In Proceedings of the 2011 IEEE/ACM Second International Conference on Cyber-Physical Systems, Chicago, IL, USA, 12-14 April 2011; pp. 67-76.

57. Zhang, F.; Huang, H. Source Selection for Real-Time User Intent Recognition toward Volitional Control of Artificial Legs. IEEE J. Biomed. Health Inform. 2012, 17, 907-914. [CrossRef]

58. Zhang, K.; Zhang, W.; Xiao, W.; Liu, H.; De Silva, C.W.; Fu, C. Sequential Decision Fusion for Environmental Classification in Assistive Walking. IEEE Trans. Neural Syst. Rehabil. Eng. 2019, 27, 1780-1790. [CrossRef] [PubMed]

59. Zhang, K.; Xiong, C.; Zhang, W.; Liu, H.; Lai, D.; Rong, Y.; Fu, C. Environmental Features Recognition for Lower Limb Prostheses toward Predictive Walking. IEEE Trans. Neural Syst. Rehabil. Eng. 2019, 27, 465-476. [CrossRef]

60. Zhang, X.; Wang, D.; Yang, Q.; Huang, H. An automatic and user-driven training method for locomotion mode recognition for artificial leg control. In Proceedings of the 2012 Annual International Conference of the IEEE Engineering in Medicine and Biology Society, San Diego, CA, USA, 28 August-1 September 2012; Volume 2012, pp. 6116-6119.

61. Zheng, E.; Wang, L.; Luo, Y.; Wei, K.; Wang, Q. Non-contact capacitance sensing for continuous locomotion mode recognition: Design specifications and experiments with an amputee. In Proceedings of the 2013 IEEE 13th International Conference on Rehabilitation Robotics (ICORR), Seattle, WA, USA, 24-26 June 2013; Volume 2013, pp. 1-6.

62. Zheng, E.; Wang, L.; Wei, K.; Wang, Q. A Noncontact Capacitive Sensing System for Recognizing Locomotion Modes of Transtibial Amputees. IEEE Trans. Biomed. Eng. 2014, 61, 2911-2920. [CrossRef]

63. Zheng, E.; Wang, Q. Noncontact Capacitive Sensing-Based Locomotion Transition Recognition for Amputees With Robotic Transtibial Prostheses. IEEE Trans. Neural Syst. Rehabil. Eng. 2016, 25, 161-170. [CrossRef]

64. Zheng, E.; Wang, Q.; Qiao, H. Locomotion Mode Recognition with Robotic Transtibial Prosthesis in Inter-Session and Inter-Day Applications. IEEE Trans. Neural Syst. Rehabil. Eng. 2019, 27, 1836-1845. [CrossRef]

65. Zhou, Z.; Liu, X.; Jiang, Y.; Mai, J.; Wang, Q. Real-time onboard SVM-based human locomotion recognition for a bionic knee exoskeleton on different terrains. In Proceedings of the 2019 Wearable Robotics Association Conference (WearRAcon), Scottsdale, AZ, USA, 25-27 March 2019; pp. 34-39.

66. Bishop, C.M. Pattern Recognition and Machine Learning; Springer: Berlin, Germany, 2006. 
67. Hargrove, L.J.; Englehart, K.; Hudgins, B. A Comparison of Surface and Intramuscular Myoelectric Signal Classification. IEEE Trans. Biomed. Eng. 2007, 54, 847-853. [CrossRef]

68. Parker, P.; Englehart, K.; Hudgins, B. Myoelectric signal processing for control of powered limb prostheses. J. Electromyogr. Kinesiol. 2006, 16, 541-548. [CrossRef]

69. Simon, A.M.; Spanias, J.A.; Ingraham, K.A.; Hargrove, L.J. Delaying ambulation mode transitions in a powered knee-ankle prosthesis. In Proceedings of the 2016 38th Annual International Conference of the IEEE Engineering in Medicine and Biology Society (EMBC), Orlando, FL, USA, 17-20 August 2016; Volume 2016, pp. 5079-5082.

70. Fisher, R.A. The use of multiple measurements in taxonomic problems. Ann. Eugen. 1936, 7, 179-188. [CrossRef]

Publisher's Note: MDPI stays neutral with regard to jurisdictional claims in published maps and institutional affiliations.

(C) 2020 by the authors. Licensee MDPI, Basel, Switzerland. This article is an open access article distributed under the terms and conditions of the Creative Commons Attribution (CC BY) license (http://creativecommons.org/licenses/by/4.0/). 